\title{
Variability of the Heat and Salt Budget in the Subtropical Southeastern Pacific Mixed Layer between 2004 and 2010: Spice Injection Mechanism
}

\author{
NiCOLAS KOLODZIEJCZYK* AND FABIENNE GAILLARD \\ IFREMER, Laboratoire de Physique des Océans, UMR 6523, CNRS/Ifremer/IRD/UBO, Plouzané, France
}

(Manuscript received 19 December 2012, in final form 28 April 2013)

\begin{abstract}
The mixed layer heat and salt budget in the southeastern subtropical Pacific are estimated using 7 years (2004-10) of Argo-profiling float data, surface fluxes, precipitation, surface velocity data, and wind observations and reanalysis. In this region, the mixed layer heat budget is characterized by a strong annual cycle mainly modulated by the shortwave radiation annual cycle. During the austral fall and winter, the shortwave radiation input minimum is overwhelmed by the heat loss mainly because of the latent heat flux. The mixed layer salt budget also presents a strong annual cycle with a minimum of salt content during the late austral winter. In contrast with the heat budget, the salt budget is mainly driven by the unresolved terms computed as the residual of the budget. Among these missing terms, the most likely candidate is the vertical turbulent mixing as a result of convection caused by the heat surface buoyancy loss and the destabilizing vertical gradient of salinity at the base of the mixed layer. This downward flux of salt at the base of the mixed layer could explain the annual spiciness injection and interannual spiciness variability in the permanent thermocline in the southeastern Pacific.
\end{abstract}

\section{Introduction}

The low-frequency dynamics of temperature in the ocean depends on whether a density anomaly exists ( Liu and Shin 1999; Schneider et al. 1999). Temperature anomalies associated with a density signature are governed by planetary wave dynamics. Temperature anomalies that are density compensated by salinity anomalies are referred to as spiciness anomalies; to a first order they have no dynamical signature and are thus advected by the mean current like a passive tracer (e.g.: Schneider et al. 1999; Lazar et al. 2001; Yeager and Large 2004; Luo et al. 2005; Tailleux et al. 2005; Laurian et al. 2006; Nonaka et Sasaki 2007; Kolodziejczyk and Gaillard 2012).

The advection of spiciness anomalies can potentially impact the interannual-to-decadal variability of tropical climate (Gu and Philander 1997; Schneider 2000, 2004),

\footnotetext{
* Current affiliation: Laboratoire d'Océanographie et du Climat, Éxpérimentation et Approches Numériques, UMR 7159 CNRS/ IRD/UPMC/MNHN, Institut Pierre-Simon Laplace, Paris, France.

Corresponding author address: Dr. Nicolas Kolodziejczyk, IFREMER, Laboratoire de Physique des Océans, UMR 6523, CNRS/Ifremer/IRD/UBO, F-29280, Plouzané, France.

E-mail: nicolas.kolodziejczyk@gmail.com
}

since they connect the surface of the eastern subtropical region, where they are generated, to the tropical regions, via the so-called thermocline bridge (Yeager and Large 2004, 2007; Luo et al. 2005; Sasaki et al. 2010; Ren and Riser 2010; Li et al. 2012; Kolodziejczyk and Gaillard 2012).

In the northeastern Pacific, stochastic atmospheric forcing is suspected to control the generation of decadal spiciness anomaly at midlatitudes (Kilpatrick et al. 2011). In the southeastern Pacific (SEP), the generation of spiciness anomalies occurs at subtropical latitudes, at both interannual and decadal time scales (Yeager and Large 2004, 2007; Luo et al. 2005; Nonaka and Sasaki 2007; Kolodziejczyk and Gaillard 2012). In the SEP, model and observational studies consistently locate the formation region of spiciness in a box defined by the $35^{\circ}$ $18^{\circ} \mathrm{S}, 120^{\circ}-85^{\circ} \mathrm{W}$ limits. In this area the pycnocline outcrops during the late austral winter, hence a direct influence of the atmospheric and surface oceanic forcing on the subducted properties (Nonaka and Sasaki 2007; Kolodziejczyk and Gaillard 2012).

In a region of meridional gradient of sea surface temperature (SST) and sea surface salinity (SSS), southeast of the surface maxima of SST and SSS, Nonaka and Sasaki (2007) have shown that the compensated temperature and salinity anomaly subducted in the permanent 
pycnocline is linked to the interannual-to-decadal variability of the meridional late winter position of the pycnocline outcrop: the farther north the outcrop reaches, the warmer and saltier (spicier) is the subducted anomaly.

Stating notable failures to link the isopycnal salinity variability to upstream changes on the density surface outcrop in some regions (Kessler 1999; Suga et al. 2000), Yeager and Large $(2004,2007)$ have proposed a theoretical picture for the mechanism of interior injection through vertical mixing at the base of the mixed layer. In the SEP, during the austral summer, the destabilizing vertical gradient of salinity is overwhelmed by the stabilizing vertical gradient of temperature. During the austral winter, the surface heat loss favors the weakening of the temperature gradient until the water column gets unstable, producing convective mixing at the base of the mixed layer. The vertical mixing leads to the formation of a strongly density-compensated layer below the mixed layer. This mechanism of spiciness injection is likely dominant in the SEP and can explain the bulk of spiciness generation on $\sigma_{\theta}=25.5$ (Yeager and Large 2007; Kolodziejczyk and Gaillard 2012).

Using a gridded product interpolated from Argo data between 2004 and 2011, Kolodziejczyk and Gaillard (2012) evidenced spice injection during the austral winters 2007 and 2010 that followed the El Niño events of 2006/07 and 2009/10. This suggests a link between tropical ENSO variability and mixed layer interannual variability, which is expressed during the austral winter season (Jin and Kirtman 2010) and is associated with interannual variability of injection of spiciness.

However, not all aspects of the hypothesis for spice injection in the SEP have been verified with observations. In particular, how do atmospheric or oceanic forcings control the mean seasonal winter spice injection? Johnson (2006) suggests that spice anomalies are surface forced by anomalous latent heat flux, but this hypothesis does not take into account the seasonality of the phenomenon (Yeager and Large 2007). Without a comparison to background climatology in the studies of Johnson (2006) and Yeager and Large (2007), there is no way of knowing how the mean seasonal atmospheric and/or oceanic forcing triggers the mean annual spice winter injection, and then, whether the winter properties show weak or strong anomalies.

This study proposes a complete diagnostic of the annual mixed layer temperature and salinity between 2004 and 2010 to understand the atmospheric and oceanic forcing coming into play in the mean seasonal spiciness injection process. The year-to-year variability of the seasonal cycle that leads to interannual injection of spice anomalies is also examined. To describe the seasonality of the atmospheric and oceanic forcing on the mixed layer in the SEP, both heat and salt mixed layer budgets are investigated using a combination of in situ data, satellite data, and atmospheric reanalyzed data. To characterize and quantify the salt flux at the base of the mixed layer, we attempt to estimate it at the base of the mixed layer as the residual of the mixed layer salt budget. This analysis will also provide a test for the hypothesis of the injection mechanisms developed by Yeager and Large (2007).

After describing the sources of data in section 2, we present the methodology in use to compute the seasonal heat and salt budget in the SEP mixed layer (section 3). In section 4, the general aspect of surface seasonality and vertical variability of the oceanic upper layer in the SEP box are discussed, then (section 5) the heat and salt mixed layer budget are presented. In section 6 , the annual-to-interannual spice injection mechanism is discussed in the light of the new results. The main results of this paper are discussed and summarized in the last section.

\section{Data and reanalysis}

The ocean data used are the Analysis, Reconstruction, Indices of the Variability of the Ocean (ARIVO) monthly gridded fields of temperature and salinity optimally interpolated from Argo and CTD observations (Gaillard et al. 2009), as done in Kolodziejczyk and Gaillard (2012). A slight change has been made relative to this last study that used a global dataset downloaded from the Coriolis data center. We discovered that many data were missing for the months of July-October 2010. The Coriolis data center has fixed the problem and issued a new release in October 2012. We have reprocessed the May-November 2010 period with the new dataset. The ARIVO fields are computed on a grid with a $0.5^{\circ} \times 0.5^{\circ}$ horizontal resolution and 152 depth levels. The vertical spacing increases from $5 \mathrm{~m}$ near surface to $20 \mathrm{~m}$ at $2000 \mathrm{~m}$. The mixed layer depth (MLD) is deduced from the monthly temperature and salinity fields according to different criteria; the reference experiment is based on a $0.5^{\circ} \mathrm{C}$ temperature change relative to the near surface $(5 \mathrm{~m})$ value. Several density criteria have also been tested.

Different atmospheric heat flux products are used in this study. The reference experiment is based on the net surface heat flux products provided by the European Centre for Medium-Range Weather Forecasts (ECMWF) dataset (http://www.ecmwf.int/research/era/do/get/erainterim). We use monthly-averaged $0.5^{\circ} \times 0.5^{\circ}$ gridded fields from ECMWF Interim Re-Analysis (ERA-Interim) available between 2004 and 2010. The second set of atmospheric products was produced by the National Centers for Environmental Prediction (NCEP)-National Center for Atmospheric Research (NCAR) Reanalysis 1 
project, which uses a state-of-the-art analysis-forecast system to perform data assimilation using past data from 1948 to present. Monthly gridded latent (LHF) and sensible (SHF) heat flux, and short- (SWR) and longwave (LWR) radiation, available for the period 2004-10 with a resolution of $1.5^{\circ} \times 1.5^{\circ}$, were downloaded for this study (http://www.esrl.noaa.gov/psd/data/gridded/data. ncep.reanalysis.html). A third net surface heat flux product consists of latent and sensible heat flux from objectively analyzed air-sea fluxes (OAFlux; Yu et al. 2008). This dataset is available on $1^{\circ} \times 1^{\circ}$ grid for the time period 1956-2012. For the purpose of this study, we used the monthly-mean fields during the period 2004-10. The $2.5^{\circ} \times 2.5^{\circ}$ gridded radiation products come from the International Satellite Cloud Climatology Project (ISCCP) datasets (1983-2009) provided by Dr. W. B. Rossow and distributed along with the OAFlux products (Zhang et al. 2004). We used monthly-mean radiative fluxes during the period 2004-09, and the missing radiative fluxes in 2010 are replaced by their ERA-Interim equivalent.

Monthly-mean estimates of near-surface chlorophyll-a (chl-a) concentration from the Sea-Viewing Wild Fieldof-View Sensor (SeaWiFS) onboard the SeaStar satellite are used to calculate the absorption of the SWR in the upper ocean. These data are available on a $0.08^{\circ} \times 0.08^{\circ}$ grid from 1997 to the present.

The atmospheric freshwater flux, the monthly evaporation, and precipitation products from ECMWF reanalysis and NECP-NCAR Reanalysis 1 are used for the period 2004-10. The third freshwater flux dataset is a combination of evaporation from the Yu et al. (2008) products (OAFlux) and precipitation from the Microwave Imager and Precipitation Radar onboard the Tropical Rainfall Measuring Mission satellite (TRMM; www.ssmi.com). The monthly-mean estimates of surface evaporation are obtained from an optimal blending of satellite retrievals and three atmospheric reanalysis product on a $1^{\circ} \times 1^{\circ}$ grid for the time period 1981-2012 (Yu et al. 2008). The reanalysis products in the Yu et al. (2008) analysis consist of the NCEP-Department of Energy (DOE) Reanalysis 1 and 2 (NCEP1\&2 reanalysis; Kanamitsu et al. 2002) and the ECMWF 40-Year Re-Analysis (Simmons and Gibson 2000). The associated precipitation dataset consists of monthly-mean precipitation estimates from the Microwave Imager and Precipitation Radar onboard the TRMM satellite. These data are available on a $0.5^{\circ} \times 0.5^{\circ}$ grid for 1998 2010. For this product we form a monthly climatology from available data to maximize the number of instances of the mean seasonal cycle.

We use two different estimates of the horizontal mixed layer velocity. First, we obtained estimates of horizontal velocity averaged in the upper $30 \mathrm{~m}$ from Ocean Surface Current Analyses-Real time (OSCAR; Bonjean and Lagerloef 2002). The velocities are deduced from satellite sea level, wind stress, and SST, using a diagnostic model. They are available on a $1^{\circ} \times 1^{\circ} \times 5$ day grid for the time period 1993-2010. The OSCAR product has the advantage of more complete spatial and temporal coverage than the ship drift and drifter-based climatologies because it uses satellite measurements, but it has the disadvantage of not being constrained by direct velocity observations. Therefore, we also use monthly fields from the Surface Currents from Diagnostic model (SCUD; Maximenko and Hafner 2010). SCUD is an International Pacific Research Center (IPRC) product, providing daily global $0.25^{\circ} \times 0.25^{\circ}$ maps of ocean surface velocities between 1999 and 2009, which includes both pressure- and wind-driven components. A simple diagnostic model combines Archiving, Validation, and Interpretation of Satellite Oceanographic data (AVISO) maps of sea level anomalies and Quick Scatterometer (QuikSCAT) surface winds and is tuned to best reproduce trajectories of real drifters, drogued at 15-m depth. Compared to OSCAR, these products offer the advantage of including in situ data from drifters in the global surface current fields. The missing year 2010 of SCUD monthly fields has been replaced by OSCAR monthly fields.

\section{Methodology}

The heat and salt budget in the mixed layer can be expressed as [see Moisan and Niiler (1998) for a complete derivation]:

$$
\begin{aligned}
\rho_{0} C_{p} h \partial_{t}\langle T\rangle= & -\rho C_{p} h\langle U\rangle \cdot \nabla\langle T\rangle \\
& -\rho C_{p}[\langle T\rangle-T(-h)] w_{e}(-h) \\
& +F_{\text {net }}+Q_{\text {pen }}+\varepsilon_{T} \text { and } \\
\rho_{0} h \partial_{t}\langle S\rangle= & -\rho_{0} h\langle U\rangle \cdot \nabla\langle S\rangle \\
& -\rho_{0}[\langle S\rangle-S(-h)] w_{e}(-h) \\
& +\langle S\rangle(E-P)+\varepsilon_{S} .
\end{aligned}
$$

The potential temperature $\left({ }^{\circ} \mathrm{C}\right)$ and the absolute salinity [ $\mathrm{g} \mathrm{kg}^{-3}$; see McDougall et al. (2009b)], are $T$ and $S$, respectively; $U$ is the horizontal velocity with $(u, v)$ the eastward and northward components of the velocities; $w_{e}$ is the entrainment velocity; $h$ the MLD; and $C_{p}$ and $\rho_{0}$ are the MLD mean heat capacity per unit volume and density, respectively. The net surface heat flux is $F_{\text {net }}$, and $E-P$ is the evaporation minus precipitation. We define the vertical average of any variable $a$ over the 
mixed layer as $\langle a\rangle=(1 / h) \int_{-h}^{0} a d z$. Here, $\boldsymbol{\nabla} \equiv\left(\partial / \partial_{x} \mathbf{i}, \partial / \partial_{y} \mathbf{j}\right)$ is the horizontal gradient operator; $x, y$, and $z$ are the eastward, northward, and upward coordinates, respectively; and $t$ is the time.

The left-hand side of Eq. (1.1) represents the heat storage tendency. The right-hand-side terms of Eq. (1.1) represent the horizontal advection of heat, the entrainmentinduced heat at the mixed layer base, the net surface heat fluxes, the amount of shortwave radiation passing through the base of the mixed layer, and the unresolved terms and the errors defined as the residual. The lhs of Eq. (1.2) represents the salt storage tendency. The rhs of Eq. (1.2) represents the horizontal advection of salt, the entrainment-induced salt at the mixed layer base, the surface freshwater fluxes, and the unresolved terms and the errors defined as a residual.

In the entrainment terms [second terms on rhs of Eqs. (1.1) and (1.2)], $w_{e}(-h)$ is the entrainment velocity, defined as

$$
w_{e}(-h)=w(-h)+\partial_{t} h+U(-h) \nabla h, \quad \text { and }
$$

the vertical velocity $w$ at the mixed layer base is estimated from the continuity equation:

$$
w(-h)=\int_{-h}^{0}\left(\frac{\partial u}{\partial x}+\frac{\partial v}{\partial y}\right) d z .
$$

It is further assumed that the horizontal divergence is depth independent in the mixed layer so that the equation of continuity reduces to

$$
w(-h)=h\left(\frac{\partial u}{\partial x}+\frac{\partial v}{\partial y}\right) .
$$

Here, $u$ and $v$ are taken from OSCAR and SCUD currents.

The penetration of shortwave flux [fourth term on rhs of Eq. (1.1)] is estimated following Sweeney et al. (2005) formula:

$$
Q_{\text {pen }}=0.47 F_{\text {sol }}\left(V_{1} e^{-h / d_{1}}+V_{2} e^{-h / d_{2}}\right),
$$

where $d_{1}$ and $d_{2}$ are the $e$-folding depths of the long visible $\left(d_{1}\right)$ and short visible and ultraviolet $\left(d_{2}\right)$ wavelengths. The parameters $V_{1}, V_{2}, d_{1}$, and $d_{2}$ are estimated using the monthly of SeaWiFS chl-a concentration, and two different algorithms provided by Morel and Antoine (1994) and Ohlmann (2003) are tested (see also Sweeney et al. 2005).

The terms $\varepsilon_{T}$ and $\varepsilon_{S}$ [last rhs terms of Eqs. (1.1) and (1.2), respectively] stand for the residuals that represent the combination of the errors and terms that cannot be directly estimated with the present dataset:

$$
\begin{aligned}
\varepsilon_{T}= & \rho_{0} C_{p}\left[-\nabla \int_{-h}^{0} \hat{U} \hat{T} d z+h A_{H} \nabla^{2}\langle T\rangle\right. \\
& \left.-K_{T} \partial_{z} T(z=-h)\right]+e_{T} \text { and } \\
\varepsilon_{S}= & \rho_{0}\left[-\nabla \int_{-h}^{0} \hat{U} \hat{S} d z+h A_{H} \nabla^{2}\langle S\rangle\right. \\
& \left.-K_{S} \partial_{z} S(z=-h)\right]+e_{S} .
\end{aligned}
$$

We note $\hat{a}=a-\langle a\rangle$ the deviation from this average. The vertical eddy diffusivity for temperature and salt are $K_{T}$ and $K_{S}$, respectively, and $A_{H}$ is the horizontal eddy diffusivity. The individual rhs terms of Eq. (6.1) represent the temperature and horizontal velocity vertical covariance, the horizontal heat diffusion, the vertical turbulent heat mixing at the base of the mixed layer, and the error made on the heat budget. The individual rhs terms of Eq. (6.2) represent the salt and horizontal velocity vertical covariance, the horizontal salt diffusion, the vertical turbulent salt mixing at the mixed layer base, and the errors made on the salt budget.

Assuming that the temperature, salinity, and horizontal velocities [first terms in Eqs. (6.1) and (6.2)] are vertically uniform in the mixed layer (no vertical shear), one can neglect the temperature and horizontal velocity vertical covariance term $\left(\nabla \int_{-h}^{0} \hat{U} \hat{T} d z\right)$ and $\left(\nabla \int_{-h}^{0} \hat{U} \hat{S} d z\right)$ in Eqs. (6.1) and (6.2). The terms are expected to be negligible compared to other terms (Swenson and Hansen 1999).

The eddy flux divergence, parameterized as the horizontal temperature and salt diffusion [second terms in Eqs. (6.1) and (6.2)] can be locally significant, as for example in the eddy exports from the South America coastal upwelling. It is assumed to have no significant impact on the heat and salt budget in the open ocean when calculations are carried out over sufficiently large areas (Colbo and Weller 2007; Toniazzo et al. 2009; Zheng et al. 2010). In the SEP, we assume that the eddy flux divergence terms are small and included in the uncertainty ranges deduced from the error on the climatological temperature, salinity, and currents (see the appendix).

Because of the lack of knowledge in the magnitude and spatial variations of the vertical mixing coefficients [third terms in Eqs. (6.1) and (6.2)], several authors (e.g., Wells et al. 2009) estimated the vertical turbulent mixing term by assuming constant coefficients in their mixed layer budget computations. This procedure is subject to high uncertainties. Since we neglected the two first rhs terms from the residual Eqs. (6.1) and (6.2), the residual is supposed to be explained by the vertical eddy 
diffusivity alone. We will first attempt to estimate the turbulent vertical flux at the base of the mixed layer by estimating the residual of the heat and salt budget; then we will deduce a scaling for the heat and salt vertical eddy diffusivity coefficients at the base of the mixed layer.

The injection of spiciness is a process of water mass formation that results from instability of the water column. The vertical buoyancy gradient $B_{z}$ is a measure of stability:

$$
B_{z}=g\left(\alpha T_{z}-\beta S_{z}\right),
$$

where $B$ is the buoyancy, and $\alpha$ and $\beta$ are the thermal expansion and haline contraction coefficients, respectively. The degree of density compensation of the vertical $T$ and $S$ gradients is quantified by the Turner angle Tu (Ruddick 1983; Yeager and Large 2007):

$$
\mathrm{Tu}=\mathrm{a} \tan \left(\frac{\alpha T_{z}+\beta S_{z}}{\alpha T_{z}-\beta S_{z}}\right) .
$$

Under conditions of stabilized water column (i.e., $T_{z}>$ 0 and $S_{z}<0$ ), the Turner angle is within $\pm 45^{\circ}$, when a destabilizing salinity gradient is concomitant with a stabilizing temperature gradient, $\mathrm{Tu}>45^{\circ}$. If $\mathrm{Tu}>71.6^{\circ}$, the process of double diffusion starts to be active (Johnson 2006); when $\mathrm{Tu}$ tends to $90^{\circ}$, the buoyancy effects of $T_{z}>0$ and $S_{z}>0$ are of opposite sign and we are close to perfect density compensation.

To focus on the generation of spiciness in the SEP, we selected a zone with a high variability of salinity in the permanent pycnocline, measured by the annual standard deviation (STD) of salinity $\sigma_{\theta}=25.5$ (Fig. 1a) and a maximum late winter Turner angle at the base of mixed layer (Fig. 1b). This leads us to define $35^{\circ}-18^{\circ} \mathrm{S}$ and $120^{\circ}-85^{\circ} \mathrm{W}$ as the boundaries of the SEP box. The number of Argo profiles in this box for each month between 2004 and 2010 is shown in the Fig. 2. During this period the coverage of Argo profiles is sufficiently dense to compute budgets with acceptable associated errors. All monthly fields used are re-interpolated on the $0.5^{\circ} \times$ $0.5^{\circ}$ ARIVO grid, and the terms of the heat and salt

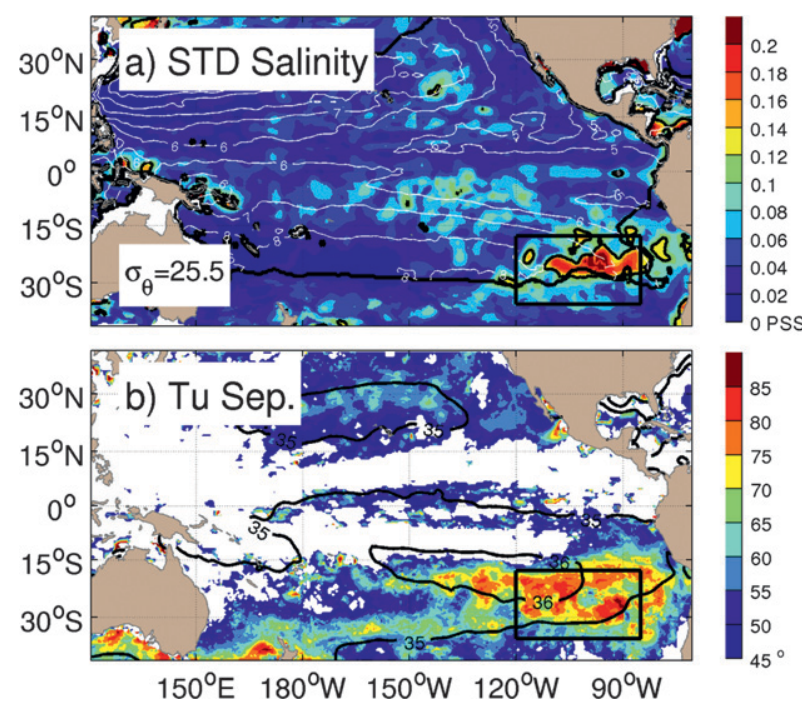

FIG. 1. (a) STD of the annual cycle of the salinity computed on the $\sigma_{\theta}=25.5$ isopycnal between 2004 and 2010. The STD $=0.12$ contours have been underlined with a black contour. Thick black contours show where the extreme equatorward outcrop reaches of the $\sigma_{\theta}=25.5$ isopycnal. The white contours are the mean streamfunctions $\left(\mathrm{m}^{2} \mathrm{~s}^{-2}\right)$ computed on the $\sigma_{\theta}=25.5$ between 2004 and 2010. (b) Mean of September values of Turner angles ( ${ }^{\circ}$; and for values $>45^{\circ}$ ) computed at the base of the mixed layer between 2004 and 2010. Thick black contours are the mean distribution of SSS during September for years 2004-10. The SEP box is the area between $35^{\circ}-18^{\circ} \mathrm{S}$ and $120^{\circ}-85^{\circ} \mathrm{W}$ outlined by the black box in both panels.

budget are computed at each of these grid points. Then, they are averaged within the SEP box. Once the monthly budgets are estimated, they are averaged over the different years for each climatological month. We have carefully estimated the error for each term following the method described in the appendix (Foltz and McPhaden 2008). Errors arise because gridded monthly fields prevent us to resolve short time scales variability due to daily surface flux variability or eddy flux contribution, and also because the different dataset and products in use present uncertainties. We have also tested the sensitivity of heat and salt budget to the different products and algorithms presented in the previous section 2 .

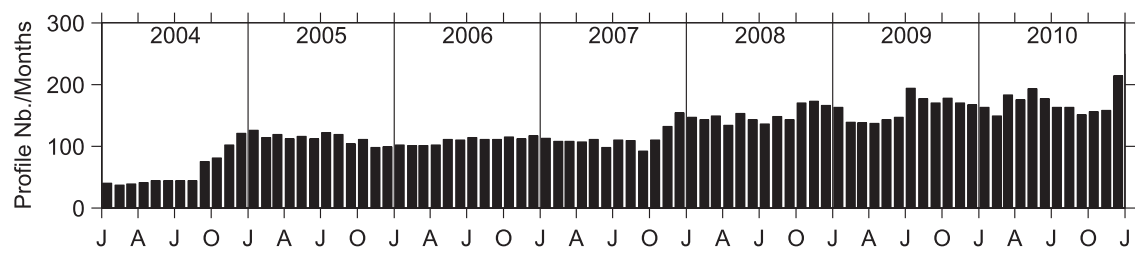

FIG. 2. Monthly distribution of the available Argo profiles in the SEP box between 2004 and 2010. 

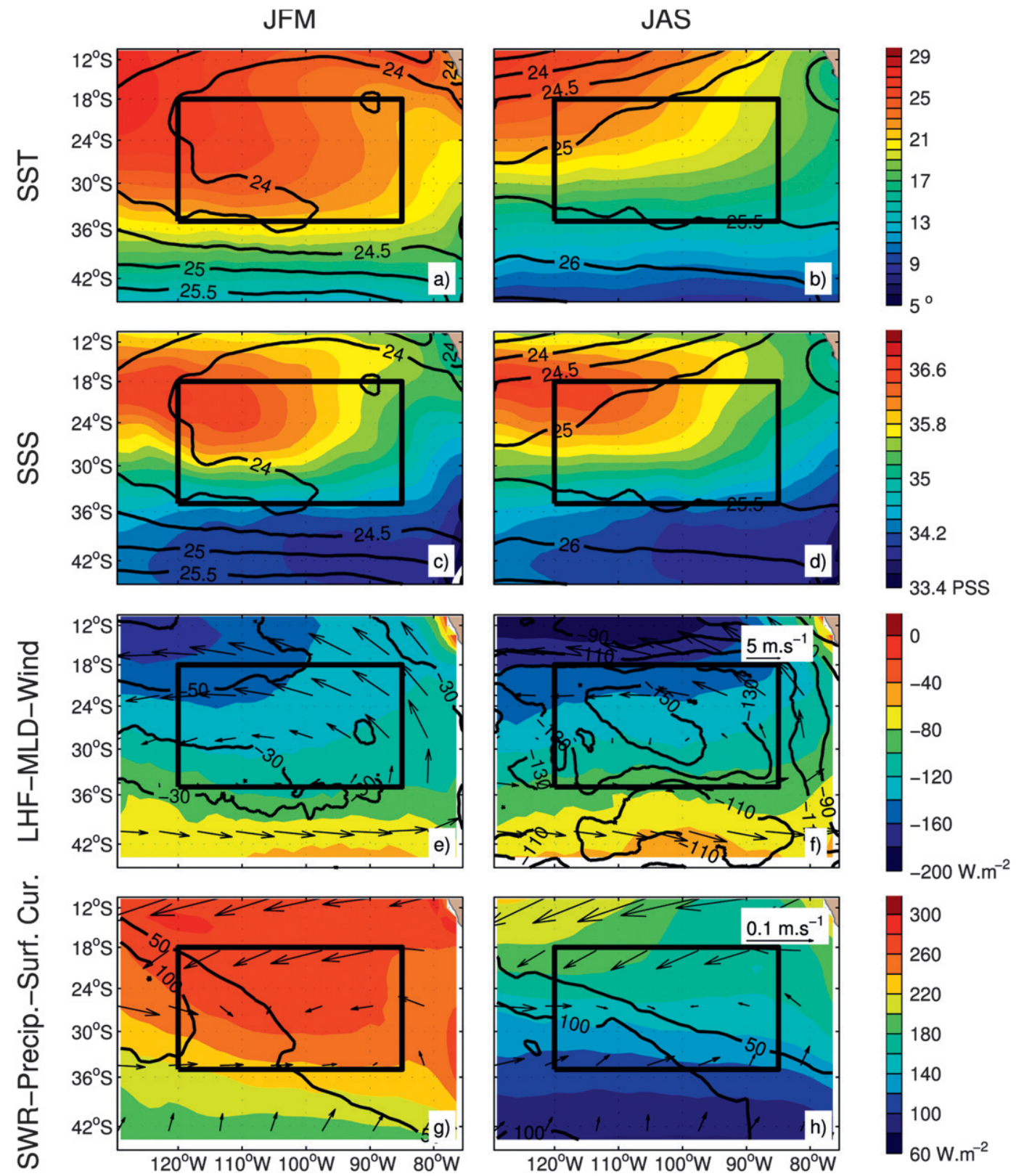

FIG. 3. Mean (left) JFM and (right) JAS distribution of: (a),(b) SST $\left({ }^{\circ} \mathrm{C}\right)$; (c), (d) SSS (PSS; color shaded) and SSD (black contours); (e),(f) latent heat flux ( $\mathrm{W} \mathrm{m}^{-2}$; color shaded), mixed layer depth ( $\mathrm{m}$; black contours), and surface wind velocity ( $\mathrm{m} \mathrm{s}^{-1}$; arrows); and $(\mathrm{g}),(\mathrm{h})$ distribution of the precipitation ( $\mathrm{mm} \mathrm{month}{ }^{-1}$; black contours); shortwave radiation ( $\mathrm{W} \mathrm{m}^{-2}$; color shaded) and surface currents $\left(\mathrm{m} \mathrm{s}^{-1}\right.$; arrows) in the SEP during 2004-10. The SEP box is shown in each panel.

\section{Seasonal variability of temperature and salinity properties}

\section{a. Surface variability}

To describe the mean seasonal variability of the surface properties in the spiciness formation region, the mean austral summer [January-March (JFM)] and winter [July-September (JAS)] distributions of SST and
SSS between 2004 and 2010 are shown in Figs. 3a,b and $3 \mathrm{c}$,d, respectively. Between JFM and JAS, the SEP region is characterized by a strong seasonal variability of the SST, SSS and sea surface density (SSD). During JFM, warm SSTs $\left(>22^{\circ} \mathrm{C}\right)$ extend southeastward to $32^{\circ} \mathrm{S}$ and $90^{\circ} \mathrm{W}$ (Fig. 3a) and are associated with SSDs lower than $24.5 \mathrm{~kg} \mathrm{~m}^{-3}$. The SSS is characterized by the subtropical salinity maximum water (SMW) centered 
around $18^{\circ} \mathrm{S}, 110^{\circ} \mathrm{W}$ that reaches values of $36.6 \mathrm{PSS}$ (Fig. $3 c)$. During JAS, in the SEP box, the SST has strongly diminished to less than $21^{\circ} \mathrm{C}$, while the surface isopycnals have migrated northward (Fig. 3b). This results in denser SSD with values greater than $25.0 \mathrm{~kg} \mathrm{~m}^{-3}$ in the SEP box. In contrast, the SSS has only slightly diminished in the SEP box with a loss of salinity less than 0.2 PSS (Fig. 3c). Moreover, it is worth noticing that between JFM and JAS, the outcrops of isopycnals have migrated northward into warmer and saltier surface waters. Compare, for example, the values of SST and SSS along the $25 \mathrm{~kg} \mathrm{~m}^{-3}$ isopycnal outcrop between JFM and JAS: SST and SSS increased approximately by $5^{\circ} \mathrm{C}$ and 2 PSS, respectively (Figs. 3a-d). This means that the spiciness of this outcropping isopycnal has increased during the austral winter.

Between JFM and JAS, the winter northward migration of the outcrops is also associated with a strong seasonal variability of the mixed layer depth within the SEP box: from less than 50-m depth during JFM to more than 150-m depth during JAS (Figs. 3e,f). This indicates a strong seasonal variability of surface buoyancy, mainly explained by the austral winter surface heat loss (Fig. 3a,b). The latent heat losses are nearly constant during the year (about $-120 \mathrm{~W} \mathrm{~m}^{-2}$; Figs. $3 \mathrm{e}, \mathrm{f}$ ), hence the seasonality of the surface heat loss may be explained by rather the strong variability of the solar input flux in the SEP box: from about $260 \mathrm{~W} \mathrm{~m}^{-2}$ during $\mathrm{JFM}$ to $160 \mathrm{~W} \mathrm{~m}^{-2}$ during JAS (Figs. 3g,h). The surface winds and currents do not show strong variability between JFM and JAS (Figs. 3g,h), neither do the precipitations that increases only slightly in the southern part of the SEP box during JAS (Figs. 3g,h).

\section{b. Vertical variability}

The mean vertical structure of the seasonal variability of the upper-ocean layer in the spiciness formation zone is investigated. Here, we compute a monthly-mean vertical profile of temperature and salinity in $z$ coordinates in the spiciness generation zone by averaging all grid points with salinity STD greater than 0.12 PSS (inside the black contours in Fig. 1).

During the austral winter from July to September, the deepening of the mixed layer is associated with a $5^{\circ} \mathrm{C}$ cooling of the surface temperature (Figs. $4 \mathrm{a}, \mathrm{c}$ ), while the temperature increases only by $0.5^{\circ} \mathrm{C}$ below the mixed layer (Figs. 4a,c). The seasonal variability of the salinity exhibits a similar evolution (Figs. 4b,d). Nevertheless, in contrast with the temperature evolution, the amplitude of the salinity growth at depth $(\sim 0.25$ PSS $)$ is nearly the same as the surface salinity decrease during the austral winter (Fig. 4d). This suggests that while a large amount of heat is likely lost toward the atmosphere, the bulk of mixed layer salt loss might be injected downward. These observations confirm the formation of temperature and salinity positive anomalies in the permanent thermocline below the mixed layer during the austral winter. During September-October, restratification operates in the upper 150-m depth but the water remains anomalously warm and salty below the mixed layer. In the interior pycnocline around $\sigma_{\theta}=25.5$, the warm and saline anomalies observed during the austral winter decrease until the beginning of the next austral winter (Fig. 4c).

The winter formation of warm temperature and high salinity anomalies in the permanent thermocline suggests the generation of a seasonal spiciness anomaly. To confirm the degree of density compensation associated with these anomalies, we investigated the contribution of the vertical gradient of temperature and salinity to the seasonal cycle of the stratification in the upper layer. The seasonal cycle of the stratification was decomposed into its temperature and salinity components: $g \alpha T_{z}$ and $g \beta S_{z}$ (Figs. 5a-c). First, it is worth noticing that the vertical gradient of salinity is destabilizing $\left(g \beta S_{z}>0\right)$, while the stability of the water column is maintained by the stronger stabilizing vertical gradient of temperature $\left(g \alpha T_{z}>g \beta S_{z}>0\right)$. During the austral summer, the shallow mixed layer is associated with a strong stratification mainly because of a sharp vertical gradient of temperature, while the weak destabilizing salinity gradient slightly reduces the stratification (Fig. 5a-c). During austral winter, the seasonal thermocline and halocline vanish and the mixed layer gets cooler and deeper. Below the mixed layer, at the depth of the permanent pycnocline ( $\left.\sigma_{\theta}=25.5-25.75\right)$, the stratification does not show strong seasonal variability, whereas sharp winter halocline and thermocline are generated during the winter season, associated with temperature and salinity positive anomalies (Figs. 4c,d). This means that density-compensated temperature-salinity anomalies have been generated just below the mixed layer during the austral winter. This is confirmed by the calculation of the seasonal evolution of the Turner angle (Fig. 5d) (Yeager and Large 2007), which exhibits values over $76^{\circ}$ during the austral winter season. This is clearly reminiscent of highly compensated water mass generation in the permanent pycnocline, that is, seasonal spiciness generation.

During austral summer, the seasonal pycnocline is mainly maintained by the sharp vertical stabilizing temperature gradient in the upper 100-m depth. The early winter surface cooling first destroys the seasonal thermocline; then the deepening of the mixed layer accelerates and reaches the top of the interior pycnocline. 

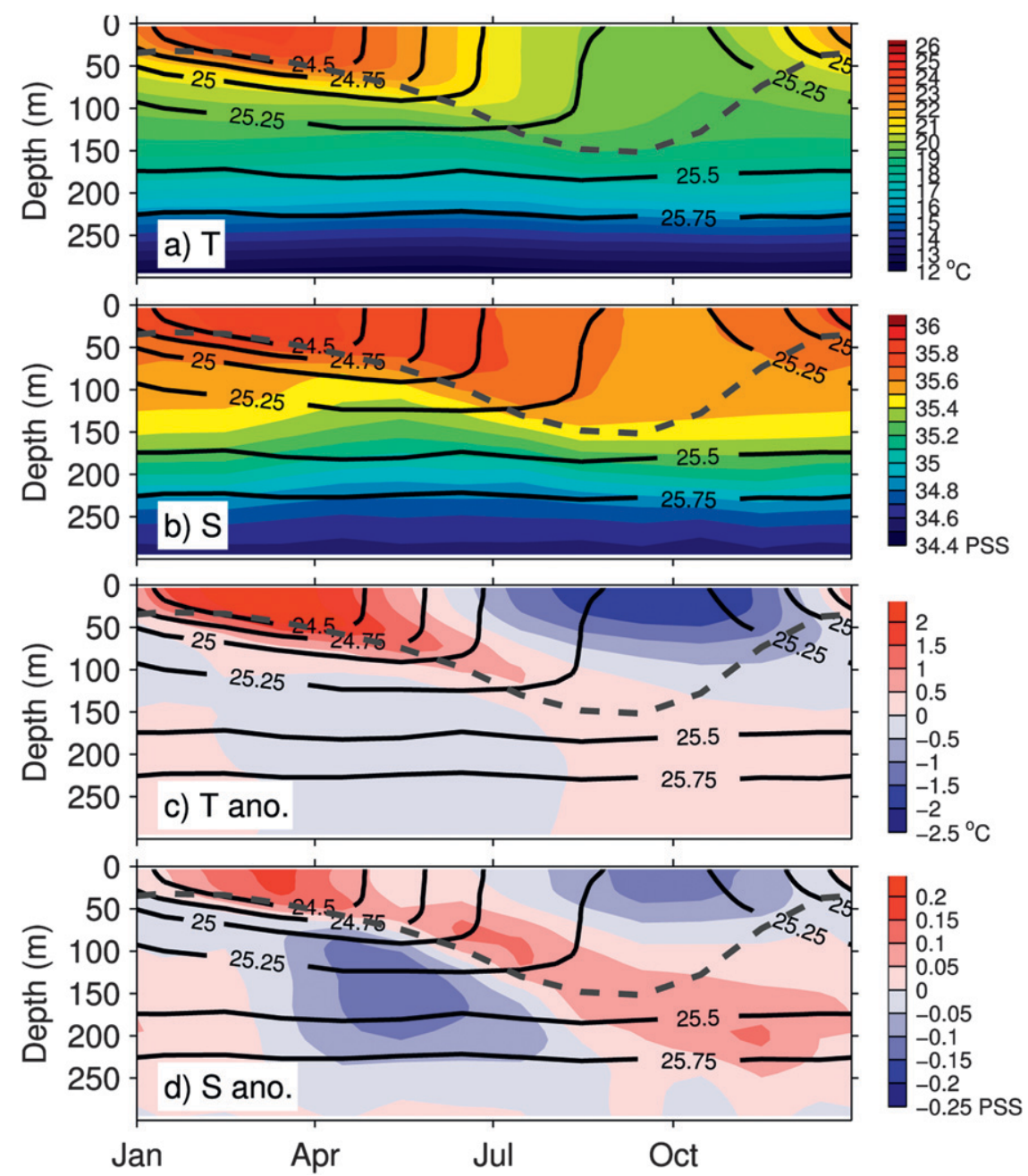

FIG. 4. Mean annual cycle of the vertical distribution of (a) temperature $\left({ }^{\circ} \mathrm{C}\right)$ and (b) salinity (PSS), annual anomaly of (c) temperature $\left({ }^{\circ} \mathrm{C}\right.$ ) and (d) salinity (PSS) computed for the grid points taken in the SEP box and in the STD $>0.12$ PSS area (see Fig. 1) within the depth range of 0-300-m between 2004 and 2010. Black contours indicate potential density contours $\left(\mathrm{kg} \mathrm{m}^{-3}\right)$. The dashed gray curve shows the mixed layer depth under the ARIVO criterion of $0.5^{\circ} \mathrm{C}$.

During austral winter, the anomalies of temperature and salinity generated at the base of the mixed layer are associated with a sharper thermocline and halocline in the permanent pycnocline, without stratification change. The high values of Turner angles in the permanent pycnocline is evidence of the injection of a seasonal spiciness anomaly at the base of the mixed layer as a result of convective mixing (Yeager and Large 2007). This layer appears to rapidly weaken between November and February (Figs. 5a-c). In the next sections, we will attempt to quantify the forcing that triggers the mixed layer heat and salt seasonal budget and to estimate the vertical turbulent flux of temperature and salt at the base of the mixed layer.

\section{Seasonal heat and salt mixed layer budget}

\section{a. Heat and salt balance}

To quantify the role of the different terms of the seasonal heat and salt mixed layer budget, we formed the monthly means for the period between 2004 and 2010 and the area average over the SEP box. The different components of the atmospheric heat flux are detailed in Fig. 6. The mixed layer gains heat by shortwave radiation all year round (red; Fig. 6). This flux shows a strong annual cycle with a minimum in austral winter (about $100 \mathrm{~W} \mathrm{~m}^{-2}$ ) and a maximum in austral summer (about $280 \mathrm{~W} \mathrm{~m}^{-2}$ ). The mean shortwave radiations gain is balanced by the sum of latent (blue), sensible and 


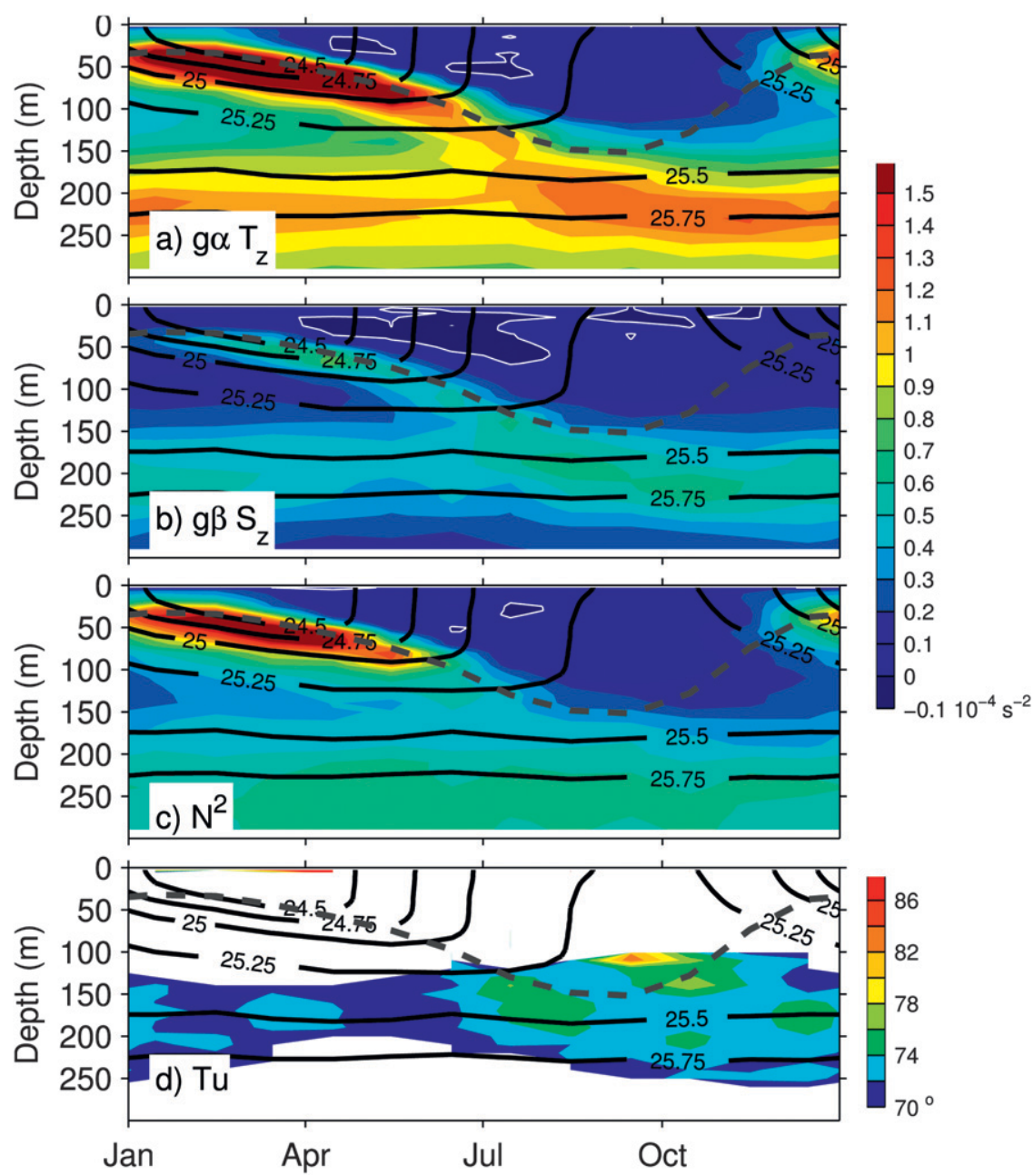

FIG. 5. Mean annual cycle of the vertical distribution of (a) the temperature and (b) the salinity contribution to the stratification $\left(\mathrm{s}^{-2}\right)$, (c) the Brunt-Väisälä frequency $\left(\mathrm{s}^{-2}\right)$, and (d) the mean Turner angle $\left(^{\circ}\right)$ computed for the grid points taken in the SEP box and in the STD $>0.12$ PSS area (see Fig. 1) within the depth range of 0-300-m between 2004 and 2010. White space indicates Turner angles $<70^{\circ}$.

longwave radiations (green) heat loss that contributes to a nearly constant cooling $\left(-200 \mathrm{~W} \mathrm{~m}^{-2}\right)$ over the year. The sum of the four atmospheric forcing terms (black) results in an annual cycle with a period of heat loss from April to September (minimum $-100 \mathrm{~W} \mathrm{~m}^{-2}$ ) and a period of heat gain from October to March (maximum $100 \mathrm{~W} \mathrm{~m}^{-2}$; Fig. 6). From April to September, the turbulent heat flux (latent and sensible) and longwave radiations dominate the reduced solar heat gain, hence a net heat loss during this season (Fig. 6).

The total atmospheric and the oceanic forcing terms for the mixed layer heat budget from Eq. (1.1) are depicted in the Figs. 7a,b. The total atmospheric heat fluxes clearly dominate the seasonal cycle (Fig. 7a). The advective and entrainment heat flux show their larger contribution from August to December, but with a magnitude five times lower than the atmospheric heat flux. Therefore, the annual cycle of the heat storage in the mixed layer is mainly explained by the net atmospheric heat forcing during the year (Fig. 7b; red). The residual exhibits a nearly constant loss of heat, averaging to $-21 \pm 5 \mathrm{~W} \mathrm{~m}^{-2}$ over the year with a slight maximum of heat loss $\left(-30 \mathrm{~W} \mathrm{~m}^{-2}\right)$ during August-September and minimum in October (Fig. 7b; black).

The mixed layer salt budget [Eq. (1.2)] is detailed in Figs. 7c,d. Evaporation dominates the atmospheric $E-P$ forcing (Fig. 7c) and contributes to a salinity increase within the mixed layer that varies between 2 and $4 \mathrm{~kg} \mathrm{~m}^{-2}$ month $^{-1}$ during the year with no clear seasonal cycle. The salt advection is negligible from January to June, then the meridional advection and entrainment each contribute to a loss of $2 \mathrm{~kg} \mathrm{~m}^{-2}$ month $^{-1}$ 


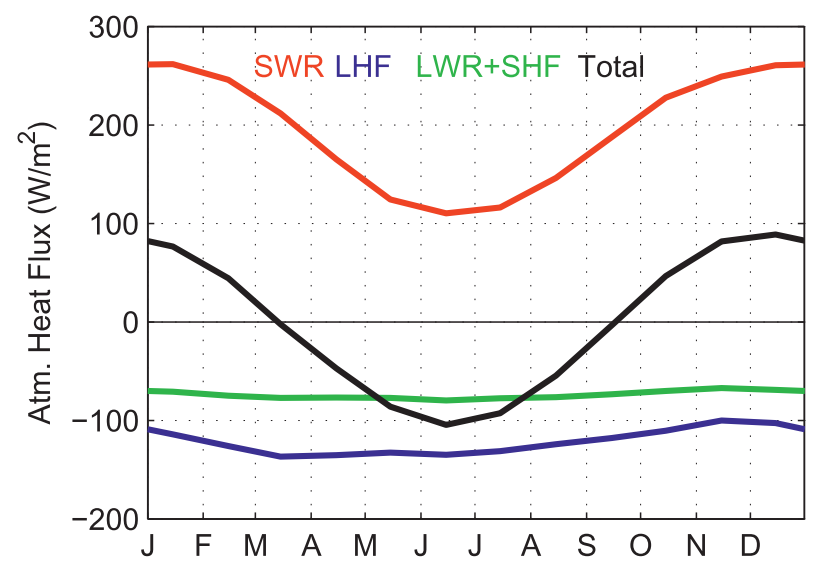

FIG. 6. Decomposition of the annual-mean cycle of the surface heat forcing between 2004 and 2010: ECMWF shortwave radiation (red), latent heat flux (blue), longwave radiation plus sensible heat flux (green), and sum of surface heat fluxes (black).

during June-August; whereas during SeptemberNovember, zonal advection and entrainment compensate each other, contributing to $2 \mathrm{~kg} \mathrm{~m}^{-2}$ month $^{-1}$ loss and gain, respectively. The forcing terms range between $\pm 3 \mathrm{~kg} \mathrm{~m}^{-2}$ month $^{-1}$ with slight seasonal variability that does not reach more than $\pm 3 \mathrm{~kg} \mathrm{~m}^{-2}$ month $^{-1}$. In contrast, the salt storage of the mixed layer shows a clear ample seasonal cycle that ranges between +4 and $-9 \mathrm{~kg} \mathrm{~m}^{-2}$ month $^{-1}$ with a maximum loss of salt between July and September during austral winter (Fig. 7d). The residual term exhibits a comparable evolution and nearly tracks the salt storage rate, with an amplitude 4 times greater in absolute value than the other forcing terms $\left(-8 \mathrm{~kg} \mathrm{~m}^{-2}\right.$ month $\left.^{-1}\right)$.

The atmospheric heat flux explains most of the seasonal cycle of the heat storage; however, the residuals have a significant contribution. In contrast, the salt budget appears to be merely controlled by unresolved terms, in particular during austral winter, independently of the atmospheric forcing. It is thus important to explore which physical process can explain these missing terms. Yeager and Large (2007) suggest that the vertical turbulent mixing at the base of the mixed layer is a prime contributor. Therefore, we will discuss the nature of the residual terms in the SEP box and test the vertical mixing hypothesis in the next section.

\section{b. Residual}

\section{1) Robustness of THE RESIDUAL}

The robustness of the residuals is examined by testing their sensitivity to a set of atmospheric heat fluxes, shortwave penetration algorithm, surface current products, and mixed layer criteria (Fig. 8).
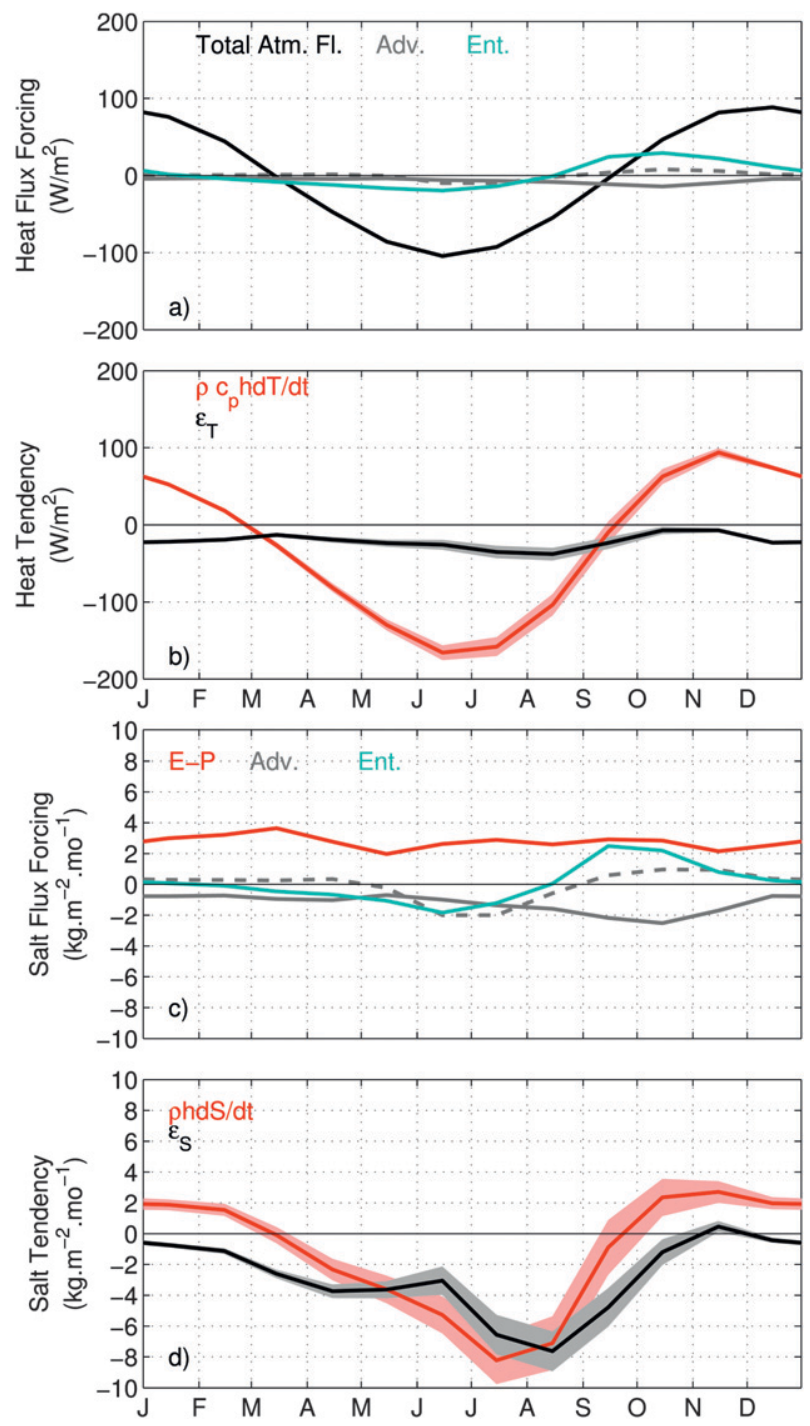

FIG. 7. (a) Annual cycle of the forcing terms from the rhs of the heat conservation Eq. (1.1) between 2004 and 2010: surface heat flux (black), zonal and meridional heat advection (solid and dashed gray, respectively), and heat entrainment (cyan). (b) Annual-mean cycle heat storage rate (red) and residual term (black), both with the associated error $\left(\mathrm{W} \mathrm{m}^{-2}\right)$. (c) Annual-mean cycle of the forcing terms from the rhs of the salt conservation Eq. (1.2) between 2004 and 2010: ECMWF evaporation minus precipitation (red), zonal and meridional salt advection (solid and dashed gray, respectively), and salt entrainment (cyan). (d) Annual-mean cycle salt storage rate (red) and residual term (black), with the associated error bars $\left(\mathrm{kg} \mathrm{m}^{-2}\right.$ month $\left.^{-1}\right)$.

The alternative use of NCEP heat flux (NCEP $E-P$ flux; green dashed), OAFlux heat flux [International Comprehensive Ocean-Atmosphere Data Set (ICOADS) evaporation minus TRMM Microwave Imager (TMI) precipitation; green dashed-dotted] products does not qualitatively affect the seasonality of the heat and salt residuals (Figs. 8a,b), but only biases the heat loss by 


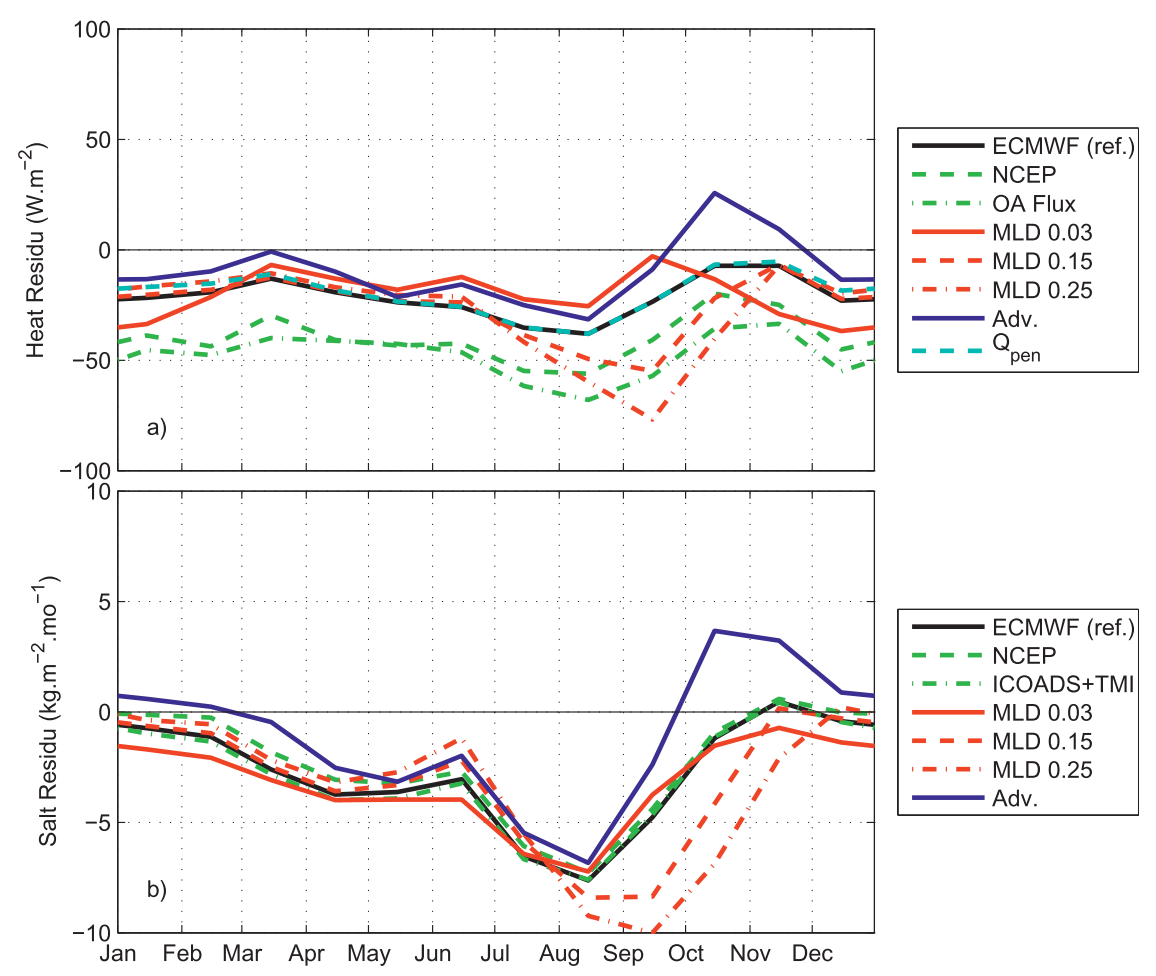

FIG. 8. (a) Sensitivity ( $\mathrm{W} \mathrm{m}^{-2}$ ) of the residual of the heat conservation Eq. (6.1) to different datasets: using ECMWF surface flux (black; by default in this study), NCEP surface flux (green dashed), OAFlux (green dashed-dotted); using a 0.03 (red solid), 0.15 (red dashed), and 0.25 (red dashed-dotted) $\mathrm{kg} \mathrm{m}^{-3}$ mixed layer depth criterion; using SCUD surface current products (blue); and changing the shortwave's penetration algorithm (dashed cyan). See text for further description. (b) Sensitivity $\left(\mathrm{kg} \mathrm{m}^{-2} \mathrm{month}^{-1}\right)$ of the residual of the salt conservation Eq. (6.2) to different datasets: using ECMWF surface flux (black; by default in this study), NCEP surface flux (green dashed), ICOADS evaporation and TMI precipitation (green dashed-dotted); using a 0.03 (red solid), 0.15 (red dashed), and 0.25 (red dashed-dotted) $\mathrm{kg} \mathrm{m}^{-3}$ mixed layer depth criterion; using SCUD surface current products (blue). See text for further description.

about $20 \mathrm{~W} \mathrm{~m}^{-2}$ (Fig. 8a). Changing the penetrative SWR algorithm from the chlorophyll-based algorithm of Ohlmann (2003) to the Morel and Antoine (1994) one (Fig. 8a) has little effect on the heat residual.

The MLD sensitivity tests were performed by using several density criteria instead of the reference ARIVO MLD criterion based on a $0.5^{\circ} \mathrm{C}$ temperature decrease. In the SEP box, the computation of the MLD by applying an ML criterion on individual profiles before interpolation, does not change significantly the MLD estimate (not shown). The criterion varies from $0.03 \mathrm{~kg} \mathrm{~m}^{-3}$ (de Boyer Montégut et al. 2004) to $0.25 \mathrm{~kg} \mathrm{~m}^{-3}$ (the Mercator temperature and salinity analysis; Foltz and McPhaden 2008), with an intermediate value of $0.15 \mathrm{~kg} \mathrm{~m}^{-3}$. The use of 0.15 and $0.25 \mathrm{~kg} \mathrm{~m}^{-3}$ criteria enhances the August-September residual heat and salt losses by about $30 \mathrm{~W} \mathrm{~m}^{-2}$ and $4 \mathrm{~kg} \mathrm{~m}^{-2}$ month $^{-1}$, respectively, but does not change the seasonality of the residuals (Figs. 8a,b). In contrast, a noticeable difference in the seasonality of the heat residual occurs when we use the $0.03 \mathrm{~kg} \mathrm{~m}^{-3}$ criterion, shifting the maximum of heat loss to July (Fig. 8a).

The use of the SCUD surface currents product, which include drifter measurements, produces a mean positive shift of $10 \mathrm{~W} \mathrm{~m}^{-2}$ in the heat residuals and $1 \mathrm{~kg} \mathrm{~m}^{-2}$ month $^{-1}$ in the salt residuals. During OctoberNovember, the shift increases to $30 \mathrm{~W} \mathrm{~m}^{-2}$ and $4 \mathrm{~kg} \mathrm{~m}^{-2} \mathrm{month}^{-1}$, for heat and salt respectively, Although, the seasonality of the residuals remains unchanged (Figs. 8a,b), it is worth noticing that the uncertainties of the current products may significantly impact the late winter subduction rate at the base of the mixed layer and modify the heat and salt budget.

This sensitivity test shows that the heat flux datasets produce a bias over the year in the heat residual of nearly $40 \mathrm{~W} \mathrm{~m}^{-2}$, with little effect on the salt residual. Current products and MLD criteria change both residuals during the austral winter (September-November), 


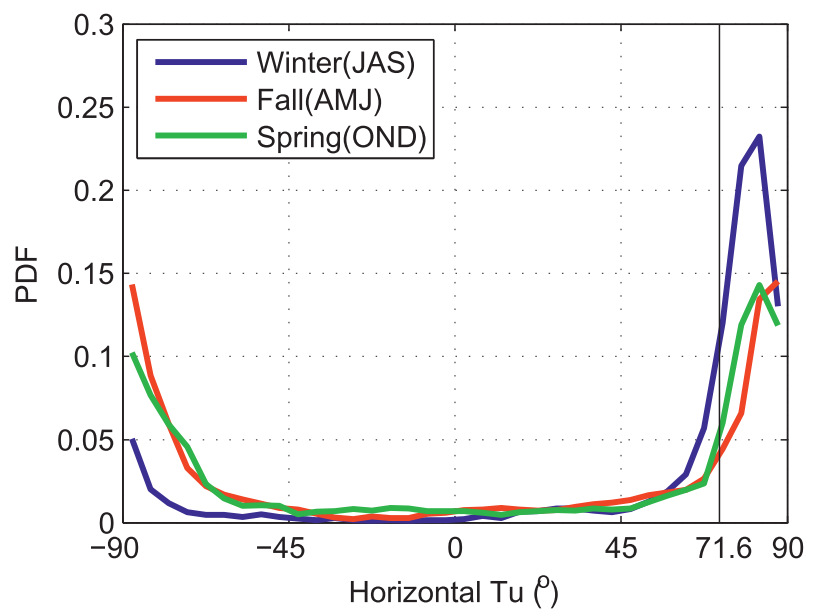

FIG. 9. PDF of the horizontal Turner angle related to the meridional gradient of the SST and SSS computed from the ARIVO fields into the SEP box during winter (blue), fall (red), and spring (green). Vertical line represents the $\mathrm{Tu}=71.6^{\circ}$.

with maximum amplitude change of $70 \mathrm{~W} \mathrm{~m}^{-2}$ for heat and $10 \mathrm{~kg} \mathrm{~m}^{-2}$ for salt. Despite this uncertainty, the heat and salt residuals show a consistent seasonal maximum loss during the austral winter (except for heat residual with MLD 0.03 in Fig. 8a) with values ranging between 0 and $60 \mathrm{~W} \mathrm{~m}^{-2}$ and between 7 and $13 \mathrm{~kg} \mathrm{~m}^{-2}$ month $^{-1}$, respectively. They mainly result from the current product that directly impacts the advection of heat and salt.

\section{2) INTERPRETATION IN TERMS OF PHYSICAL PROCESSES}

In addition to the accumulation of the errors and biases from directly estimated terms, the heat and salt balance residuals also represent the sum of unresolved physical processes among which vertical turbulent mixing is the most likely candidate.

To characterize the enhanced mixing in the mixed layer during the winter season, we first compute the probability density function (PDF) of the surface horizontal Turner angle relative to the meridional gradient: $\mathrm{Tu}=\mathrm{a} \tan \left[\left(\alpha T_{y}+\beta S_{y}\right) /\left(\alpha T_{y}-\beta T_{y}\right)\right]$ for fallspring season, as defined by Yeager and Large (2007). Figure 9 shows that the mixed layer thermohaline properties tend to be more compensated (PDF $>0.2$ for $\mathrm{Tu}>$ $80^{\circ}$ ) during the austral winter than during the fall and spring season. This increase of the horizontal Turner angle in the mixed layer during winter suggests stronger horizontal and vertical mixing (Ferrari and Paparella 2003; Boccaletti et al. 2007; Cole et al. 2010), which leads to reduce the density gradients, but maintains the thermohaline gradients.

Therefore, we suspect that the increased winter residuals are mainly related to the vertical turbulent mixing

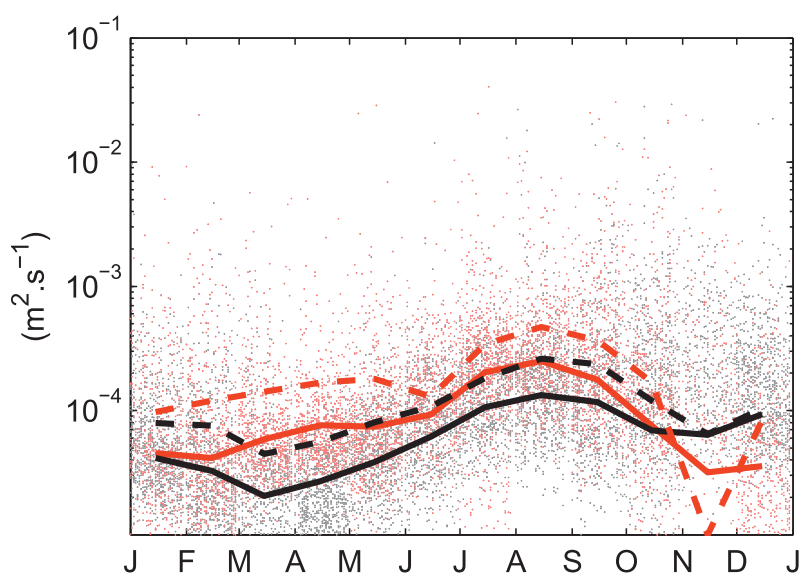

FIG. 10. Computation of the monthly-mean $K_{T}$ (black) and $K_{S}$ (red) coefficients of vertical eddy diffusivity for heat and salt $\left(\mathrm{m}^{2} \mathrm{~s}^{-1}\right)$ : from the ARIVO optimally interpolated profiles (dashed); monthly mean of individual profiles (solid); and individual profiles (dots).

(Yeager and Large 2007). To check this hypothesis, we compute the monthly-mean vertical turbulent mixing coefficient $K_{T}$ and $K_{S}$ (Foltz et al. 2010; de Boisséson et al. 2010; Wade et al. 2011) from heat and salt residuals, using Eqs. (6.1) and (6.2) approximated as

$$
\begin{aligned}
& \varepsilon_{T}=-\rho_{0} C_{p} K_{T} \partial_{z} T \text { and } \\
& \varepsilon_{S}=-\rho_{0} K_{S} \partial_{z} S,
\end{aligned}
$$

where the vertical gradients $\partial_{z} T$ and $\partial_{z} S$ are computed in two different ways: (i) from ARIVO optimally interpolated profiles and (ii) from individual Argo profiles. The vertical gradients are then averaged in the SEP box for each month between 2004 and 2010. The ratio of the residual on the vertical gradients $\partial_{z} T$ and $\partial_{z} S$ will provide a monthly estimate of the $K_{T}$ and $K_{S}$. The seasonal evolution of the values of $K_{T}$ and $K_{S}$ computed with ARIVO field (dashed lines) and individual profiles (solid lines and points) are reported in the Fig. 10. The estimated $K_{T}$ and $K_{S}$ show a relative constant value from November to May ranging between 0.5 and $1.5 \times$ $10^{-4} \mathrm{~m}^{2} \mathrm{~s}^{-1}$, they increase during austral fall and winter (JAS; Table 1) reaching more than $2-4 \times 10^{-4} \mathrm{~m}^{2} \mathrm{~s}^{-1}$, thus one order of magnitude larger than the spring and summer values. As expected, estimates obtained from optimally interpolated, and thus filtered, profiles, are higher than those obtained from the individual Argo profiles. We compare the austral winter (JAS) estimates of vertical mixing coefficients value with the nondoublediffusivity coefficients in the permanent pycnocline $\left(0.1-0.2 \times 10^{-4} \mathrm{~m}^{2} \mathrm{~s}^{-1}\right.$; Ledwell et al. 1993) and the double-diffusive values $\left(0.5 \times 10^{-4} \mathrm{~m}^{2} \mathrm{~s}^{-1}\right.$; St. Laurent 
TABLE 1. Comparison between the vertical mixing coefficients estimated in the SEP box and the vertical mixing coefficients for different regimes of vertical mixing in the permanent thermocline estimated in the literature.

\begin{tabular}{ccccc}
\hline \hline $\begin{array}{c}\text { Mixing } \\
\text { coefficient }\end{array}$ & $\begin{array}{c}\text { Nondouble diffusion } \\
\text { Ledwell et al. (1993) }\end{array}$ & $\begin{array}{c}\text { Double diffusion } \\
\text { St. Laurent and Schmitt (1999) }\end{array}$ & $\begin{array}{c}\text { Turbulent } \\
\text { Large et al. (1994) }\end{array}$ & $\begin{array}{c}\text { JAS SEP box estimates } \\
\text { (this study) }\end{array}$ \\
\hline$K_{S}\left(10^{-4} \mathrm{~m}^{2} \mathrm{~s}^{-1}\right)$ & $0.1-0.2$ & $0.5\left(\right.$ at $\left.\mathrm{Tu} \sim 81^{\circ}\right)$ & $>1 \rightarrow 10^{3}$ & $2.2-3.9$ \\
$K_{T}\left(10^{-4} \mathrm{~m}^{2} \mathrm{~s}^{-1}\right)$ & $0.1-0.2$ & $0.1\left(\right.$ at $\left.\mathrm{Tu}<74^{\circ}\right)$ & $>1 \rightarrow 10^{3}$ & $1.2-2.3$ \\
\hline
\end{tabular}

and Schmitt 1999) in Table 1. The values deduced here are in the lower range of the values proposed by Yeager and Large (2007) for the vertical turbulent mixing (Table 1 ) that could correspond to convective turbulent mixing. Therefore, following Yeager and Large (2007), the turbulent vertical mixing coefficients should satisfy

$$
K_{T}=K_{S}=K
$$

The difference between the estimations of temperature and salinity mixing coefficients are likely attributable to the greater sensitivity of heat budget residual to the atmospheric fluxes and mixed layer depth estimate [section $5 b(1)]$. These uncertainties could lead to an underestimation of heat loss toward the atmosphere and an overestimation of the heat loss toward the mixed layer base, hence a lower vertical turbulent mixing coefficient. Therefore, we are more confident in the vertical turbulent mixing coefficient for salt estimate, and we use it as the effective vertical turbulent mixing coefficient for both salt and heat.

Following, Yeager and Large (2007), the mixing at the base of the mixed layer is suggested to be buoyancy driven, through the surface buoyancy flux and convection. However, at the surface, the flux of turbulent kinetic energy as a result of the wind stress may also provide some additional mixing into the mixed layer. To further investigate the main contributor to the seasonal variability of residuals associated with the vertical turbulent mixing, we examine the mixed layer buoyancy seasonal cycle.

On the one hand, the surface atmospheric buoyancy flux $B$ is the sum of the flux associated with the surface heat flux $B_{h}$ and of the flux associated with the freshwater flux $B_{w}$ (Wade et al. 2011):

$$
B=B_{h}+B_{w} .
$$

The component due to the net surface heat flux is written $B_{h}=\left(\alpha / C_{p}\right) F_{\text {net }}$ and the component due to the freshwater flux is given by $B_{w}=\beta \rho S(E-P)$. On the other hand, the surface flux of turbulent kinetic energy is a function of the sum of the cube of the friction velocity $u_{*}$ and the surface buoyancy flux. The friction velocity is defined as $u_{*}=\left(\tau / \rho_{0}\right)^{1 / 2}$, where $\tau$ is the surface wind stress magnitude, and $\rho_{0}$ is the density of surface seawater.

We compared the seasonal variability of the mixed layer depth to the atmospheric buoyancy forcing due to the surface heat and freshwater fluxes and the friction velocity to identify potential correlations (in Figs. 11a-c). The principal contributor to the buoyancy flux seasonality is the surface heat loss, which is dominated by shortwave radiations (Fig. 6 and Fig. 11b). No wellmarked seasonality nor correlation with the cycle of the salt residual is observed in the friction velocity or the Ekman pumping (Figs. 11c,d). Therefore, it suggests that mixing at the base of the mixed layer may be due to convective mixing (buoyancy driven) rather than to the flux of turbulent kinetic energy at the surface (wind driven). The heat loss reduces the temperature vertical gradient at the base of the mixed layer during the austral winter, while the destabilizing vertical salinity gradient leads to destabilize the water column. Thus, convection operates and leads to a downward diapycnal flux of salinity (and temperature) at the base of the mixed layer. This results in a strong density-compensated layer (spiciness) just below the mixed layer. During the austral winter, the enhancement of the vertical eddy diffusivity coefficients estimated from our data supports the notion of active convection at the base of the mixed layer.

\section{Injection of spiciness}

\section{a. Seasonal injection}

As proposed by Yeager and Large (2007), the diapycnal convective flux of salinity at the base of the mixed layer is the key process involved in spice injection. Following Kolodziejczyk and Gaillard (2012), the winter spice injections on the $\sigma_{\theta}=25.5$ are characterized by an increase of the vertical Turner angle values on this surface from July to September (see Fig. 5d). As suggested by the mixed layer salt budget, the turbulent salt flux at the base of the mixed layer may be the dominant process that acts in reducing the salinity of the mixed layer by injecting salt below.

Spice injection in the interior pycnocline can be evaluated by monitoring the time evolution of the $S\left(\sigma_{\theta}\right)$ curve (Yeager and Large 2007). Figure 12 shows such 

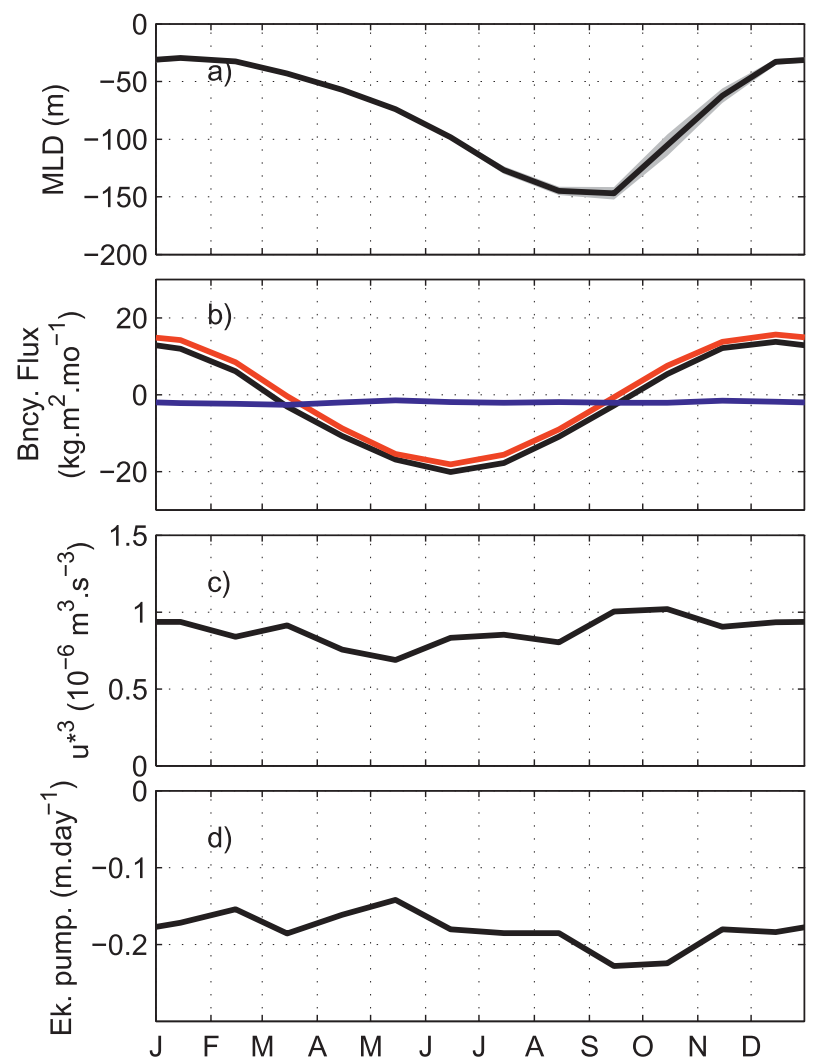

FIG. 11. (a) Mean annual cycle of the mixed layer depth (m). (b) Mean annual cycle of the freshwater flux (blue) and heat flux (red), sum of both (black) of buoyancy flux computed with ECMWF $\left(\mathrm{kg} \mathrm{m}^{-2}\right.$ month $\left.^{-1}\right)$. (c) Mean annual cycle of the friction velocities $\left[u_{*}^{3}=\left(\tau / \rho_{0}\right)^{3 / 2} ; \mathrm{m}^{3} \mathrm{~s}^{-3}\right]$. (d) Mean annual cycle of the Ekman pumping velocity $\left(\mathrm{m}^{-1 a y}{ }^{-1}\right)$.

curves for the mean monthly profiles of Fig. 4 between May and November. We observe a clear steepening of the $S\left(\sigma_{\theta}\right)$ curve in the permanent pycnocline during the winter season (the density range from $\sigma_{\theta}=25.37$ to $\sigma_{\theta}=$ 25.8, materialized by the vertical lines). Salinity increases by approximately 0.2 PSS along $\sigma_{\theta}=25.5$, although this isopycnal remains deeper than the mixed layer base. The amount of injected salinity diminishes with depth to vanish below $\sigma_{\theta}=25.8$. In contrast, in the mixed layer (the lightest density of each profile) the salinity decreases, while the density increases subject to the winter loss of buoyancy through surface cooling.

In this context, we should see salinity decreases in the mixed layer balanced by salinity increases deeper in the permanent-interior pycnocline, particularly in the compensated layer at the base of the late winter mixed layer. Therefore, we have computed the climatological monthly average of the salinity change rate over the course of each year in the interior pycnocline as:

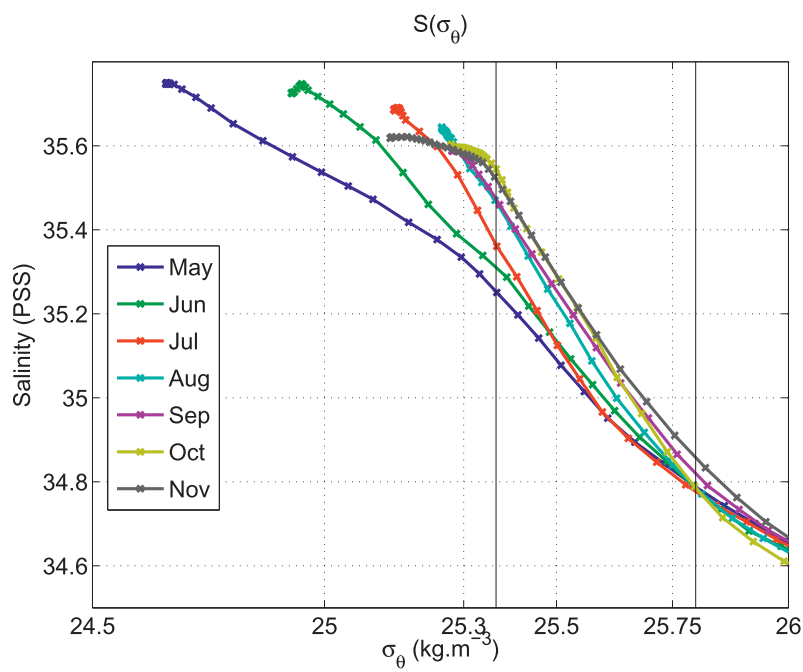

FIG. 12. Winter evolution of the upper-ocean water column $S\left(\sigma_{\theta}\right)$ climatological profiles in the SEP and in the STD $>0.12$ PSS area (as in Figs. 1 and 4) between May and November. Vertical lines indicate the interior pycnocline where spice injection takes place (between $\sigma_{\theta}=25.37$ and $\sigma_{\theta}=25.8$, respectively).

$$
S_{\text {int }}=\rho_{0} h_{\text {int }} \frac{\partial\langle S\rangle_{\text {int }}}{\partial t}
$$

where $h_{\text {int }}$ is the layer of where takes place the injection, defined between $\sigma_{c}$ the isopycnal where the salinity change between the late winter profiles becomes negligible $\left(\sigma_{c}=25.8\right.$; see Fig. 12 and Fig. 13a) and $\sigma_{b}$ the density surface of the late winter at base of the mixed layer $\left(\sigma_{b}=\mathrm{MLBD}_{\max } \sim 25.37\right.$ on the average; Fig. 13a). We define the average over the vertical in the interior layer of any variable as $\langle a\rangle_{\text {int }}=\left(1 / h_{\text {int }}\right) \int_{\sigma_{c}}^{\sigma_{b}} a d z$. The intermediate layer between the mixed layer and the late winter sea surface density [referred to as remnant mixed layer in Cole et al. (2010)] is not taken into account: no injection can take place in this layer because it vanishes during the winter season (Fig. 13a).

The interior salt storage rate is compared with the mixed layer salt storage rate and the salt residual interpreted as vertical turbulent mixing at the base of the mixed layer (Fig. 13b). During the winter season, both curves (cf. solid and dashed black and red curves in Fig. 13b) show a good anticorrelation that confirms the redistribution of salt from the mixed layer toward the interior during the austral winter. Furthermore, during the austral winter the sum of the mixed layer salt residual and the interior pycnocline salt storage is not significant (blue bars), which strongly suggests the compensation of the salinity loss of the mixed layer and the salinity gain in the interior pycnocline.

From spring to summer, the mixed layer and the permanent pycnocline are separated by an intermediate 

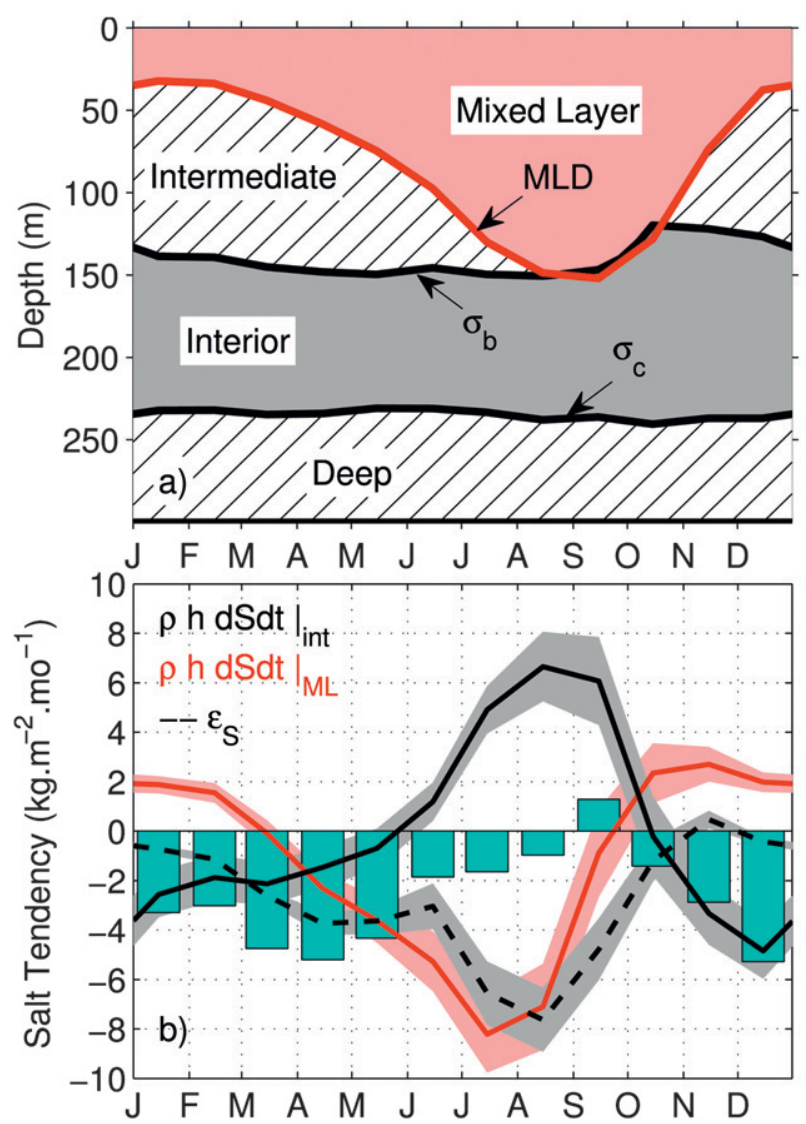

FIG. 13. (a) Mean annual cycle of the mixed layer (red area); and interior pycnocline (gray area) encompassed between the late winter density at the base of the mixed layer $\sigma_{b}(\sim 25.37)$ and the density surface $\sigma_{c}(=25.8)$. Hatched areas represent the intermediate layer and deep layer where no injection occurs. (b) Evolution of the mean averaged salt storage rate (red); residual term (dashed black) and the interior mean averaged salt storage rate (black) with the associated error bars. The aqua bars represent the monthly differences between the interior salt storage rate and the residual term $\left(\mathrm{kg} \mathrm{m}^{-2}\right.$ month $\left.^{-1}\right)$.

layer and other terms may contribute to the salt budget variability in the interior pycnocline. These terms could be the equatorward advection of salt out of the SEP box (Kolodziejczyk and Gaillard 2012); and salt fingering mixing that erodes the injected salinity during the spring (Johnson 2006).

As a conclusion, the decrease of salinity in the mixed layer is concomitant with the increase of the Turner angle on the $\sigma_{b}=25.5$ isopycnal surface that reaches values greater than $71.6^{\circ}$ during August (Fig. 5d). During the austral winter the salinity in the interior pycnocline has increased consistently with the salinity loss from the mixed layer (Figs. 12 and 13). These results strongly suggest that, during the austral winter, the convective diapycnal fluxes at the base of the mixed layer contribute to vertically redistribute salinity over
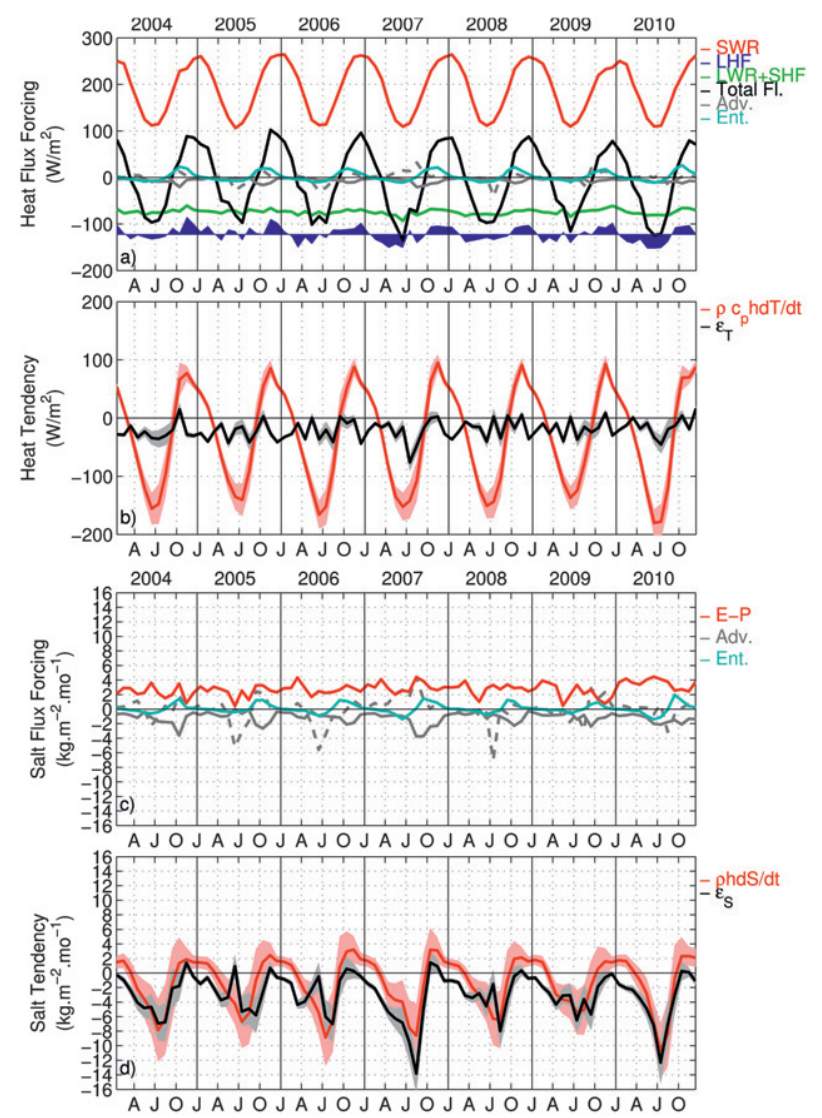

FIG. 14. (a) Evolution of the monthly forcing terms from the rhs of heat conservation Eq. (1.1) between 2004 and 2010: ECMWF shortwave radiation (red), latent heat flux (blue), longwave radiation plus sensible heat flux (green), sum of surface heat flux (black), zonal and meridional heat advection (solid and dashed gray, respectively), and heat entrainment (cyan). (b) Evolution of the monthly heat storage rate (red) and residual term (black) with the associated error bars between 2004 and $2010\left(\mathrm{~W} \mathrm{~m}^{-2}\right)$. (c) Evolution of the monthly forcing terms from the rhs of the salt conservation Eq. (1.2) between 2004 and 2010: ECMWF Evaporation minus precipitation (red), zonal and meridional salt advection (solid and dashed gray, respectively), and salt entrainment (cyan). (d) Evolution of the monthly salt storage rate (red) and residual term (black) with the associated error bars between 2004 and $2010\left(\mathrm{~kg} \mathrm{~m}^{-2}\right.$ month $\left.^{-1}\right)$.

the water column by injecting compensated salinity anomalies in the interior pycnocline.

\section{b. Interannual variability}

The study of the mean seasonal variability of the mixed layer heat and salt budget has shown the robustness of the diapycnal injection of spiciness as part of the seasonal cycle of the mixed layer variability. It is the interannual variability of the intensity of this salinity flux and changes in surface conditions that create positive or negative spiciness anomalies below the mixed layer. This feature is revealed in Fig. 14, which depicts the time 


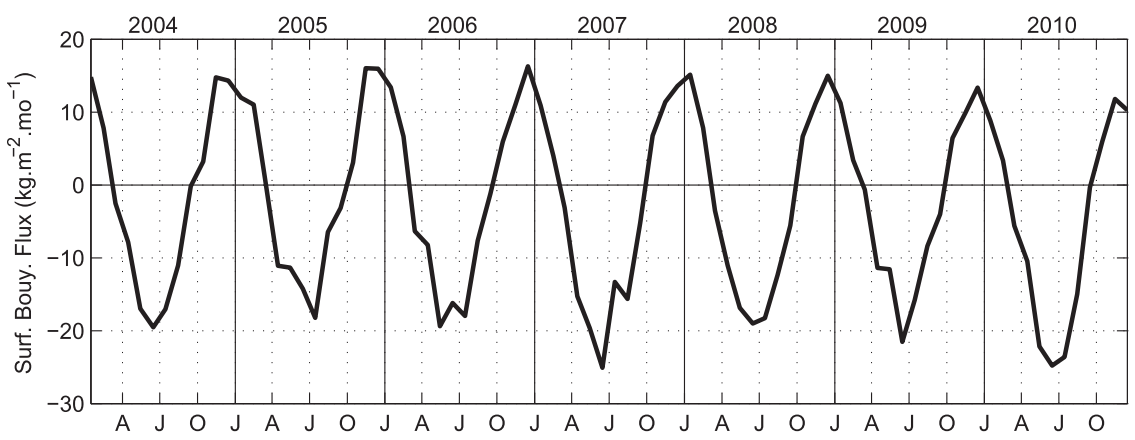

FIG. 15. Evolution of the monthly surface buoyancy flux in the SEP box between 2004 and 2010 $\left(\mathrm{kg} \mathrm{m}^{-2}\right.$ month $\left.^{-1}\right)$.

series of heat and salt budgets for the period 2004-10. The heat budget variability is dominated, as previously described, by a strong seasonal cycle mainly because of the atmospheric heat flux (black curve; Fig. 14a). During the austral winters 2007 and 2010, anomalous negative atmospheric heat fluxes are reported, which are mainly explained by the anomalous latent heat loss during these winters (blue curve; Fig. 14a). Then, the mixed layer exhibits a larger amount of heat loss, which leads to a larger loss of buoyancy through atmospheric exchanges (Fig. 15). During these two winters, a larger residual of salt is also revealed in Fig. 14d, which suggests a larger diapycnal salt flux from the mixed layer toward the interior pycnocline. It is compatible with the injection of spiciness anomaly that has been reported to be stronger during these two years (Kolodziejczyk and Gaillard 2012).

\section{Discussion and conclusions}

This study provides a first attempt to close the seasonal heat and salt budgets in the mixed layer of the SEP region using in situ observations. The heat budget reveals that the austral winter cooling is mainly explained by the reduced atmospheric shortwave radiation that does not compensate latent heat loss during the winter. In contrast, the salt loss from the mixed layer during the same season is mainly explained by unresolved processes at the base of the mixed layer, interpreted as the vertical convective mixing. The convective mixing is produced by the combination of the buoyancy loss as a result of the winter cooling and the destabilizing effect of the salinity gradient. This vertical convective mixing produces a diapycnal flux of heat and salt at the base of the mixed layer that enhances the gradient of both salinity and temperature just below the mixed layer within the permanent pycnocline. It forms the strongly compensated layer of spiciness in the permanent pycnocline.
These results evidence a consistent scenario of winter formation of spiciness at the base of the mixed layer. They confirm the Yeager and Large (2007) hypothesis of vertical mixing as the process responsible for the interior injection of spiciness at the base of the mixed layer and give a complete scenario: (i) Most of the buoyancy loss in the mixed layer is due to the surface heat loss. At seasonal time scale, the heat loss is controlled by the reduction of the solar heat flux and dominance of the latent heat loss during the winter. At interannual time scale, interannual anomalous latent heat loss is responsible for greater heat loss during 2007 and 2010. (ii) The destabilizing effect of the salinity gradient produces convective mixing at the base of the mixed layer. (iii) It produces a diapycnal flux of heat and salt at the base of the mixed layer that enhances the salinity and temperature vertical gradient in a highly compensated layer just below the mixed layer. (iv) The total loss of salt from the mixed layer is mostly due to enhanced vertical turbulent mixing at the base of the mixed layer. (v) The amount of spiciness generated within the pycnocline during the winter is consistent with the salt loss from the mixed layer. (vi) During austral spring, the highly compensated layer is strongly eroded probably by double diffusive mixing (Johnson 2006; Yeager and Large 2007) or equatorward advected out of the SEP box (Kolodziejczyk and Gaillard 2012).

In model studies, Large et al. (1994) reported vertical eddy diffusivity in the surface boundary layer up to three orders of magnitude higher than the permanent pycnocline diffusivity (0.1-0.2 $\mathrm{m}^{2} \mathrm{~s}^{-1}$; Ledwell et al. 1993). With only one order of magnitude greater, our value of vertical eddy diffusivity at the base of the mixed layer is probably underestimated because we used monthlyaveraged fields. The use of monthly ARIVO fields also filters the high-frequency variability within the mixed layer. Indeed, some convection events occur on time scales of a few days. The computation of $K_{T}$ and $K_{S}$ from individual profiles reveals a very large dispersion that 
suggests that the heat flux at the base of the mixed layer could be about two orders of magnitude larger than the double-diffusivity coefficient (Table 1 ). However, the cumulative effect of convection on the salt and heat loss in the mixed layer is well established with our dataset. The mixing coefficient should be seen as a mean rate of convection during the winter period, which could be, as previously calculated, one to two orders of magnitude greater when estimated on an individual profile. The encouraging results of this study show the remarkable power of the Argo network.

Significant uncertainties are associated with our estimates of the horizontal salt and heat advection and entrainment. Errors in salinity advection are caused by a combination of uncertainties in mixed layer depth, horizontal salinity and salt gradients, and mixed layer velocity. Among the neglected terms, the horizontal eddy component of the advection of salt and heat could be the next term responsible for the mixed layer budget variability. Although eddies can export heat and salt from the eastern boundary currents into the interior SEP (Colbo and Weller 2007), Zheng et al. (2010) have shown in a model study that this eddy heat flux has little impact far away from the coast in the SEP. Eddy activity is rather located in particular areas in the north and south of our SEP box. In any case, the resolution of the Argo network is not sufficient to access the mesoscale and only a dedicated experiment will permit one to infer the role of eddy advection upon the mixed layer seasonal variability.

The ARIVO fields based on ARGO data provide a reliable climatological background state and the time evolution of temperature and salinity properties, providing insight into the interannual variability of ocean spiciness anomalies. Using this dataset, Kolodziejczyk and Gaillard (2012) identified two strong events of positive spiciness injection in the SEP during the austral winters of 2007 and 2010. In the present study, we find an excess of salt flux residual at the base of the mixed layer during these same winters. Furthermore, we show that the anomalously high-salinity injections are driven by a greater than normal latent heat loss, confirming the role of the atmospheric forcing in the formation of spiciness in the interior pycnocline at annual-to-interannual time scale (Kessler 1999; Johnson 2006; Yeager and Large 2004, 2007).

This study establishes that spice injection is the main mechanism for the generation of spiciness in the SEP. The amount of the density compensated water injected within the permanent pycnocline (about between $\sigma_{\theta}=$ 25.37 and $\sigma_{\theta}=25.8$ in the SEP), can be deduced from the salinity convective flux at the base of the mixed layer during the winter (inducing an increase of about
0.2 PSS) and this convective flux appears to be explained by the buoyancy loss from the mixed layer toward the atmosphere.

Acknowledgments. This work was funded by Ifremer project "Ocean and climate-SO-Argo" and by CNESTOSCA project "GLOSCAL." N. Kolodziejczyk was supported by an Ifremer post-doctoral grant. The ERAInterim reanalyses products are provided by European Centre for Medium-Range Weather Forecasts. The NCEP reanalysis derived data provided by the NOAA/ OAR/ESRL PSD, Boulder, Colorado (www.esrl.noaa. gov/psd/). The global ocean heat flux and evaporation products (OAFlux) were provided by the WHOI OAFlux project (http://oaflux.whoi.edu) funded by the NOAA Climate Observations and Monitoring (COM) program. The TMI data are produced by Remote Sensing Systems and sponsored by the NASA Earth Science MEaSUREs DISCOVER Project. Data are available at www.remss.com. In situ datasets were provided by Coriolis data center (http://www.coriolis.eu.org/). The authors thank Gilles Reverdin for useful comments on the manuscript and two anonymous reviewers for suggestions and corrections that substantially improved the manuscript.

\section{APPENDIX}

\section{Error Estimates}

We first used the monthly errors in salinity and temperature provided at each grid point in the ARIVO fields. The error is given by the climatological variance at each point weighted by a percent of error that reflects the number of available data used in the monthly optimal interpolation. Measurement errors are generally about one order of magnitude smaller than the sampling errors, which are about $\sim(0.04-0.2)$. Errors in velocity components are estimated through monthly STD of 5-day OSCAR fields and monthly STD of daily SCUD fields. The errors for each parameter are then analytically propagated in the heat and salt budget terms calculation following Foltz and McPhaden (2008) and Foltz et al. (2010). The error on the vertical average of the temperature and salinity in the mixed layer is given at each grid point by $e_{\Xi_{\iota}}=\sqrt{(1 / N) \sum_{k=1}^{N} e_{\xi_{k, i}}^{2}}($ with $\Xi=T, S$ ), where $e_{\xi}$ and $e_{\Xi}$ are the errors at each grid point following the horizontal $(i)$ and the vertical $(k)$, respectively, and for the vertical average, and $N$ is the number of vertical levels in the mixed layer. Errors in the mixed layer salt and heat tendency are then estimated as $e_{\partial \Xi / \partial t}=\left(\sqrt{e_{\Xi_{t-1}}^{2}+e_{\Xi_{t+1}}^{2}}\right) / 2 \Delta t$, where $\Delta t=1$ 
month. Errors in zonal salt and heat advection are estimated as $e_{u \mathrm{adv}}=\sqrt{e_{u}^{2}(\partial \Xi / \partial x)^{2}+u^{2} e_{\partial \Xi / \partial x}^{2}}$, with an analogous expression for $e_{v \text { adv }}$. Here, we have $e_{\partial \Xi \partial x}=$ $\left(\sqrt{e_{\Xi_{x+1}}^{2}+e_{\Xi_{x}}^{2}}\right) / \Delta x$ and $\Delta x=0.5^{\circ}$. We have assumed that the errors for the different quantities are uncorrelated.

The methodology described above gives error estimates for the mixed layer heat and salinity storage rate, horizontal advection, and entrainment at each $0.5^{\circ} \times$ $0.5^{\circ}$ grid point. To estimate errors in the SEP box, we follow Smith et al. (1994) and estimate the degrees of freedom for each area-averaged quantity as

$$
\operatorname{DoF}=N\left(\sum_{i=1}^{N} \sigma_{i}^{2}\right)\left[\sum_{i=1}^{N-1} \sigma_{i}^{2}+2 \sum_{i=1}^{N-1} \sum_{j=i+1}^{N} \operatorname{cov}\left(x_{i}, x_{j}\right)\right]^{-1} .
$$

Here $\sigma_{i}^{2}$ is the variance at grid point $i, N$ is the number of grid points in the SEP box, and $\operatorname{cov}\left(x_{i}, x_{j}\right)$ is the covariance between the quantity at grid point $i$ and $j$. For the extreme case in which the time series in each pair of grid points are uncorrelated, $\mathrm{DoF}=N$, and when the times series are perfectly correlated, $\mathrm{DoF}=1$. Using Eq. (A1), monthly climatological errors for the areaaveraged quantities are estimated as

$$
e_{\mathrm{ave}}=\frac{1}{\mathrm{DoF}} \sqrt{\frac{\mathrm{DoF}}{N} \sum_{i=1}^{N} e_{i}^{2}}
$$

where $e_{i}$ is the error for grid point $i$.

In addition to the formal error analysis described above we have provided a comparison of several different horizontal velocities products, atmospheric fluxes products, mixed layer depth criterion, and shortwave radiation penetration algorithm to further quantify the uncertainty in mixed layer heat and salt budget.

\section{REFERENCES}

Boccaletti, G., R. Ferrari, and B. Fox-Kemper, 2007: Mixed layer instability and restratification. J. Phys. Oceanogr., 37, 2228-2250.

Bonjean, F., and G. S. E. Lagerloef, 2002: Diagnostic model and analysis of the surface currents in the tropical Pacific Ocean. J. Phys. Oceanogr., 32, 2938-2954.

Colbo, K., and R. Weller, 2007: The variability and heat budget of the upper ocean under the Chile-Peru stratus. J. Mar. Res., 65 , 607-637.

Cole, S. T., D. L. Rudnick, and J. A. Colosi, 2010: Seasonal evolution of the upper ocean horizontal structure and the remnant mixed layer. J. Geophys. Res., 115, C04012, doi:10.1029/2009JC005654.

de Boisséson, E., V. Thierry, H. Mercier, and G. Caniaux, 2010: Mixed layer heat budget in the Iceland Basin from Argo. J. Geophys. Res., 115, C10055, doi:10.1029/2010JC006283.

de Boyer Montégut, C., G. Madec, A. S. Fischer, A. Lazar, and D. Iudicone, 2004: Mixed layer depth over the global ocean:
An examination of profile data and a profile-based climatology. J. Geophys. Res., 109, C12003, doi:10.1029/2004JC002378.

Ferrari, R., and F. Paparella, 2003: Compensation and alignement of the thermohaline gradient in the ocean mixed layer. J. Phys. Oceanogr., 33, 2214-2223.

Foltz, G. R., and M. J. McPhaden, 2008: Seasonal mixed layer salinity balance of the tropical North Atlantic. J. Geophys. Res., 113, C02013, doi:10.1029/2007JC004178.

_ mixed layer heat balance of the southwestern tropical Indian Ocean. J. Phys. Oceanogr., 40, 947-965.

Gaillard, F., E. Autret, V. Thierry, P. Galaup, C. Coatanoan, and T. Loubrieu, 2009: Quality control of large Argo datasets. J. Atmos. Oceanic Technol., 26, 337-351.

Gu, D., and S. G. H. Philander, 1997: Interdacadal climate fluctuation that depend on exchanges between the tropics and extratropics. Science, 275, 805-807, doi:10.1126/science.275.5301.805.

Jin, D., and B. P. Kirtman, 2010: How the annual cycle affects the extratropical responses to ENSO. J. Geophys. Res., 115, D06102, doi:10.1029/2009JD012660.

Johnson, G. C., 2006: Generation and initial evolution of a mode water $\theta$-s anomaly. J. Phys. Oceanogr., 36, 739-751.

Kanamitsu, M., W. Ebisuzaki, J. Woollen, S. K. Yang, J. J. Hnilo, M. Fiorino, and G. L. Potter, 2002: NCEP-DOE AMIP II Reanalysis (R-2). Bull. Amer. Meteor. Soc., 83, 1631-1643.

Kessler, W. S., 1999: Interannual variability of the subsurface high salinity tongue south of the equator at $165^{\circ}$ E. J. Phys. Oceanogr., 29, 2038-2049.

Kilpatrick, T., N. Schneider, and E. Di Lorenzo, 2011: Generation of low-frequency spiciness variability in the thermocline. J. Phys. Oceanogr., 41, 365-377.

Kolodziejczyk, N., and F. Gaillard, 2012: Observation of interannual variability of spiciness in the Pacific pycnocline. J. Geophys. Res., 117, C12018, doi:10.1029/2012JC008365.

Large, W. G., J. C. McWilliams, and S. C. Doney, 1994: Oceanic vertical mixing: A review and a model with nonlocal boundary layer parametrization. Rev. Geophys., 32, 363-403.

Laurian, A., A. Lazar, G. Reverdin, K. Rodgers, and P. Terray, 2006: Poleward propagation of spiciness anomalies in the North Atlantic Ocean. Geophys. Res. Lett., 33, L13603, doi:10.1029/2006GL026155.

Lazar, A., R. Murtugudde, and A. J. Busalacchi, 2001: A model study of temperature anomaly propagation from subtropics to tropics within the South Atlantic thermocline. Geophys. Res. Lett., 28, 1271-1274.

Ledwell, J. R., A. J. Watson, and C. S. Law, 1993: Evidence for slow mixing across the pycnocline from an open-ocean tracerrelease experiment. Nature, 364, 701-703.

Li, Y., F. Wang, and Y. Sun, 2012: Low-frequency spiciness variations in the tropical Pacific Ocean observed during 2003-2012. Geophys. Res. Lett., 39, L23601, doi:10.1029/2012GL053971.

Liu, Z., and S.-I. Shin, 1999: On the thermocline ventilation of active and passive tracers. Geophys. Res. Lett., 26, 357-360.

Luo, Y., L. M. Rothstein, R.-H. Zhang, and A. J. Busalacchi, 2005: On the connection between South Pacific subtropical spiciness anomalies and decadal equatorial variability in an ocean general circulation model. J. Geophys. Res., 110, C10002, doi:10.1029/2004JC002655.

Maximenko, N., and J. Hafner, 2010: SCUD: Surface currents from diagnostic model. IPRC Tech. Note 5, 19 pp.

McDougall, T. J., D. R. Jackett, and F. J. Millero, 2009b: An algorithm for estimating Absolute Salinity in the global ocean. Ocean Sci. Discuss., 6, 215-242. 
Moisan, J. R., and P. P. Niiler, 1998: The seasonal heat budget of the North Pacific: Net heat flux and heat storage rates (1950-90). J. Phys. Oceanogr., 28, 401-421.

Morel, A., and D. Antoine, 1994: Heating rate within the upper ocean in relation to its bio-optical state. J. Phys. Oceanogr., 24, $1652-1665$.

Nonaka, M., and H. Sasaki, 2007: Formation mechanism for isopycnal temperature-salinity anomalies propagating from the eastern South Pacific to the equatorial region. J. Climate, 20, $1305-1315$

Ohlmann, J. C., 2003: Ocean radiant heating in climate models. J. Climate, 16, 1337-1351.

Ren, L., and S. C. Riser, 2010: Observations of decadal time scale salinity change in the subtropical thermocline of the North Pacific Ocean. Deep-Sea Res. II, 57, 1161-1170.

Ruddick, B., 1983: A practical indicator of stability of the water column to double-diffusive activity. Deep-Sea Res., 30, 1105-1107.

Sasaki, Y. N., N. Schneider, N. Maximenko, and K. Lebedev, 2010: Observational evidence for propagation of decadal spiciness anomalies in the North Pacific. Geophys. Res. Lett., 37, L07708, doi:10.1029/2010GL042716.

Schneider, N., 2000: A decadal spiciness mode in the tropics. Geophys. Res. Lett., 27, 257-260.

_ 2004: The response of the tropical climate to the equatorial emergence of spiciness anomaly. J. Climate, 17, 1083-1095.

— A. J. Miller, M. A. Alexander, and C. Deser, 1999: Subduction of decadal North Pacific temperature anomalies: Observations and dynamics. J. Phys. Oceanogr., 29, 1056-1070.

Simmons, A. J., and J. K. Gibson, 2000: The ERA-40 project plan. European Centre for Medium-Range Weather Forecasts Tech. Rep. ERA-40, 63 pp.

Smith, T. M., R. W. Reynolds, and C. F. Ropelewski, 1994: Optimal averaging of seasonal sea surface temperature and associated confidence intervals (1860-1989). J. Climate, 7, 949-964.

St. Laurent, L., and R. W. Schmitt, 1999: The contribution of salt fingers to vertical mixing in the North Atlantic tracer release experiment. J. Phys. Oceanogr., 29, 1404-1424.

Suga, T., A. Kato, and K. Hanawa, 2000: North Pacific tropical water: Its climatology and temporal changes associated with the climate regime shift in the 1970s. Prog. Oceanogr., 47, 223-256.

Sweeney, C., A. Gnanadesikan, S. M. Griffies, M. J. Harrison, A. J. Rosati, and B. L. Samuel, 2005: Impacts of shortwave penetration depth on large-scale ocean circulation and heat transport. J. Phys. Oceanogr., 35, 1103-1119.

Swenson, M. S., and D. V. Hansen, 1999: Tropical Pacific Ocean mixed layer heat budget: The Pacific cold tongue. J. Phys. Oceanogr., 29, 69-81.

Tailleux, R., A. Lazar, and C. J. C. Reason, 2005: Physical and dynamics of density-compensated temperature and salinity anomalies. Part. I: Theory. J. Phys. Oceanogr., 35, 849-864.

Toniazzo, T., C. R. Mechoso, L. C. Shaffrey, and J. M. Slingo, 2009: Upper-ocean heat budget and ocean eddy transport in the south-east Pacific in a high-resolution coupled model. Climate Dyn., 35, 1303-1329, doi:10.1007/s00382-009-0703-8.

Wade, M., G. Caniaux, and Y. du Penhoat, 2011: Variability of the mixed layer heat budget in the eastern equatorial Atlantic during 2005-2007 as inferred using Argo floats. J. Geophys. Res., 116, C08006, doi:10.1029/2010JC006683.

Wells, N. C., S. A. Josey, and R. E. Hadfield, 2009: Toward closure of the regional heat budget in the North Atlantic using Argo floats and surface flux dataset. Ocean. Sci., 5, 59-72, doi:10.5194/ os-5-59-2009.

Yeager, G. S., and W. G. Large, 2004: Late winter generation of spiciness on subducted isopycnals. J. Phys. Oceanogr., 34, 1528-1546.

- and _ 2007: Observational evidence of winter spice injection. J. Phys. Oceanogr., 37, 2895-2019.

Yu, L. S., X. Jin, and R. A. Weller, 2008: Multidecade global flux datasets from the objectively analyzed air-sea fluxes (OAFlux) Project: Latent heat and sensible heat fluxes, ocean evaporation, and related surface meteorological varaibles. Woods Hole Oceanographic Institution OAFlux Project Tech. Rep. OA-2008-01, 64 pp. [Available online at http://oaflux.whoi.edu/pdfs/OAFlux_TechReport_3rd_ release.pdf.]

Zhang, Y., W. B. Rossow, A. A. Lacis, V. Oinas, and M. I. Mishchenko, 2004: Calculation of radiative fluxes from the surface to top of atmosphere based on ISCCP and other global data sets: Refinements of the radiative transfer model and the input data. J. Geophys. Res., 109, D19105, doi:10.1029/2003JD004457.

Zheng, Y., T. Shinoda, G. N. Kiladis, J. Lin, E. J. Metzger, H. E. Hurlburt, and B. S. Giese, 2010: Upper-ocean processes under the stratus cloud deck in the southeast Pacific Ocean. J. Phys. Oceanogr., 40, 103-120. 